\title{
A view of developing patterns of investment in AMT through empirical taxonomies: new evidence
}

\author{
Macarena Sacristán Díaz ${ }^{\mathrm{a}, *}$, José A.D. Machuca ${ }^{\mathrm{a}}$, \\ María José Álvarez-Gil ${ }^{\text {b }}$ \\ a Dpto. de Economía Financiera y Dirección de Operaciones, GIDEAO Research Group, Universidad de Sevilla, \\ Avda. Ramón y Cajal, 1, 41018 Sevilla, Spain \\ b Dpto. de Economía de la Empresa, Universidad Carlos III de Madrid, c/Madrid, 126, 28903 Getafe, Madrid, Spain
}

\begin{abstract}
In line with the theoretical premises of the research, the aim of this paper is two-fold: firstl , to determine whether there are different patterns of advanced manufacturing technology (AMT) investment behavior in the Andalusian aeronautical industry that can be associated with different technology strategies, as in other sectors and geographical areas and, secondly, to identify possible similarities or differences from previous research, such as Boyer et al. [J. Operations Manage. 14 (4) (1996) 297-313] and Jonsson [Int. J. Operations Production Manage. 20 (12) (2000) 1446-1474]. A survey of the 20 plants in the population was conducted via postal questionnaire between July 1999 and April 2001, with a structured interview being held at a later date. A cluster analysis was performed which allowed a taxonomy with three groups of plants to be established: traditionalists, designers and investors. These three groups differ from each other with regard to their AMT investments, industrial activity, size and degree of integration. Differences between the groups in company performance cannot be appreciated. Although the results apparently seem to back up most of the finding of previous works biased to larger companies, they do bring certain aspects into question regarding the explanation for the way the groups are formed. The three critical factors which determine AMT investment in the sector are the company's being of a certain minimum size, undergoing a period of expansion, and type of activity. (C) 2003 Elsevier B.V. All rights reserved.
\end{abstract}

Keywords: Advanced manufacturing technologies; Technology management; Operations strategy

\section{Introduction}

There have been various studies (Lefebvre et al., 1992; Chen, 1996) that demonstrated the inadequacy of Porter's (1987) basic strategies for dealing with technological strategies and, in particular, advanced manufacturing technology (AMT) investment strate-

\footnotetext{
* Corresponding author. Tel.: +34-954-557-627; fax: +34-954-557-570.

E-mail address: macarena-sd@us.es (M. Sacristán Díaz).
}

gies. An alternative approach is the development of taxonomies that may provide strategic configuration with a discriminatory ability by establishing groups of companies that share a number of common characteristics, attributes or relationships (Boyer et al., 1996; Jonsson, 2000).

In the present study, we firs aim to identify a taxonomy define by the different patterns of investment in AMT followed by companies-mostly smalland medium-sized enterprises (SMEs) - in a specifi industrial sector, located in a pre-determined geo- 


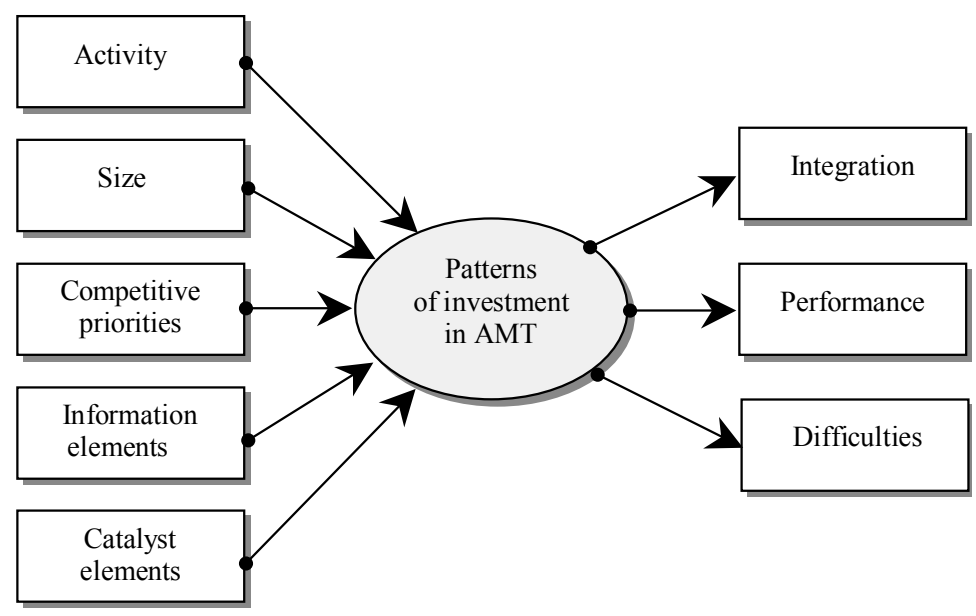

Fig. 1. Theoretical model.

graphical zone. We shall specificall consider the aeronautical sector in Andalusia, southern Spain, ${ }^{1}$ for the period July 1999 to April 2001. This leads us on to the second objective of this research, which is to identify any possible similarities and differences from previous studies and the reasons for these.

The working hypotheses put forward to explain the reasons why the different groups are formed point in two directions. Firstly, there is the influenc that a variety of different factors (activity, size, competitive priorities, and information and catalyst elements) may have on these patterns. Secondly, there are possible differences between groups with respect to the level to which their activities and company performance are integrated. A graphical representation of the theoretical model incorporating these relationships can be found in Fig. 1. There has been scant analysis of the effect had by competitive priorities in previous studies, and we are not aware of any analysis that links information and catalyst elements with levels of AMT investment. The third objective we have therefore set for ourselves is the provision of new data not found in previous works, albeit in an exploratory phase and with no view to generalization.

Various factors led us to conclude that conducting an empirical analysis into the Andalusian aeronau-

\footnotetext{
${ }^{1}$ Only the construction of aeroplanes should be understood here, as there are no aerospace activities in the region, which is why the use of the term 'aerospace' has been avoided.
}

tical sector was particularly interesting and opportune. Firstly, this sector is strategically important, not only for Andalusian industry, but also for Spain's and the European Union's as a whole; secondly, it is extremely technologically-intensive and as such is a potential user of a wide and diverse range of AMT; thirdly, it was an inducement that this sector had not previously been the subject of many specifi scientifi studies into AMT management. Finally, the companies in the sector are, for the main part, small- and medium-sized, with $40 \%$ having a workforce of under 50 employees. We therefore thought our study could contribute to mitigating the lack of research aimed at identifying investment taxonomies for smaller plants; as we shall see, existing work has thus far been highly biased towards larger companies. The Andalusian aeronautical industry includes a number of Construcciones Aeronáuticas S.A. (CASA) manufacturing plants. CASA, the Spanish national aeronautical company, has been a member of the Airbus Consortium since 1971 and of the European Aeronautic, Defense and Space Company (EADS) since its creation in 2000. The sector also includes a number of SME ancillary firm with customers who number not only other Spanish aeronautical companies, such as CASA itself, but also foreign companies, such as Boeing. According to statements made by the President of Boeing Europe, Richard L. James, in 1999, in the Seville area alone there were more than fi e companies manufacturing 
no fewer than 3500 different parts for the Boeing 717.

It was always considered imperative to include the CASA group factories in the analysis. On the one hand, this was a prime necessity if the whole population were to be studied, and, on the other, it allowed a clear company size distinction to be made. The fact that all the factories belonged to the same group does not distort the results, as CASA was not part of EADS at the time of our study. Furthermore, each of the group's factories devised its technology strategy independently from the others, not only as far as the choice of equipment is concerned, but also with respect to the equipment evaluation process, even though the fi nal choice was subject to approval by Head Offic (as confirme by the Heads of the Engineering Departments that we consulted).

Section 2 reviews literature in order to establish what the possible advantages associated with the use of taxonomies are, as well as to identify the theoretical parameters on the basis of which our hypotheses can be formulated. The hypotheses are set out in Section 3, and in Section 4, they are tested empirically. In Section 5, the results are analyzed and discussed. Finally, in Section 6, conclusions are drawn and possible future lines of research are proposed.

\section{Literature review}

The purpose of taxonomies, unlike typologies, is not to defin company ideals, but rather to classify organizations into comprehensive or mutually exclusive groups (Doty and Glick, 1994) that provide a multidimensional vision of the organizations studied (Bozarth and McDermott, 1998). The usefulness and applicability of this approach in the area of operations has been demonstrated in a special issue of the Journal of Operations Management (Boyer et al., 2000).

In Table 1, a summarized list can be found of some of the studies devoted to developing taxonomies for company strategies in which the relevant technology is explicitly considered. From a study of 100 multinational companies, Stobaugh and Telesio (1983) developed a taxonomy of three operations strategies: technology-driven, marketing-intensive and low-cost. Some years later, Roth and Miller (1992) (cited in Harrison, 1995), identifie three groups of companies
Table 1

Technology strategy taxonomies

\begin{tabular}{ll}
\hline Authors (year) & Proposed groups \\
\hline $\begin{array}{l}\text { Stobaugh and Telesio } \\
\text { (1983) }\end{array}$ & $\begin{array}{l}\text { Technology-driven, } \\
\text { marketing-intensive and low-cost } \\
\text { Roth and Miller (1992) }\end{array}$ \\
$\begin{array}{l}\text { Weaklings, middlemen and } \\
\text { superstars }\end{array}$ \\
Miller and Roth (1994) & $\begin{array}{l}\text { Caretakers, marketers and } \\
\text { innovators }\end{array}$ \\
Harrison (1995) & Weak competitors, middlemen \\
& and strong competitors \\
\hline
\end{tabular}

differentiated by their manufacturing capabilities, which they designated as weaklings, middlemen and superstars. In a subsequent study, Miller and Roth (1994) proposed a new taxonomy for operations strategies in which three groups of companies may again be distinguished, designating them as caretakers, marketers and innovators. In research conducted into more than 100 Australian companies, Harrison (1995) identifie a taxonomy with three differentiated groups according to their manufacturing capability, specifying them as weak competitors, middlemen and strong competitors.

Relevant literature dealing with an analysis of AMT investment patterns is fairly recent and still relatively scarce. There are, however, two articles especially devoted to the subject. The firs is a study by Boyer et al. published in 1996; the second is by Jonsson and was published in 2000. Boyer et al. (1996) conducted an empirical study based on a sample of 202 US metal-working companies and took for the purposes of analysis three basic types of AMT: design, manufacturing and administrative. A cluster analysis was performed and enabled the companies to be classifie into four differentiated groups according to their investment patterns: traditionalists, generalists, high investors and designers.

The traditionalist group, made up of a large proportion of the companies, is characterized by the fact that it does not undertake any big investments in advanced design, manufacturing or administration technologies, apparently preferring to place its trust in more conventional technologies. The generalist companies are thus called because they make substantial investments in all three types of AMT technologies, although not to the same degree as the high investors. This latter group is at the forefront of investment in advanced 
Table 2

AMT investment taxonomy (from information in Boyer et al., 1996)

\begin{tabular}{lllll}
\hline & $(1)$ Traditionalists & (2) Generalists & (3) High investors & (4) Designers \\
\hline Design & {$[2,3,4]$} & {$[1,3,4]$} & {$[1,2,4]$} & {$[1,2,3]$} \\
Manufacturing & {$[2,3,4]$} & {$[1,3,4]$} & {$[1,2,4]$} & {$[1,2,3]$} \\
Administrative & {$[2,3,4]$} & {$[1,3,4]$} & {$[1,2,4]$} & {$[1,2,3]$} \\
Size & {$[3]$} & & {$[1]$} & No differences \\
Activity & No differences & No differences & No differences & {$[2,3]$} \\
Integration & {$[2,3]$} & {$[1,3,4]$} & {$[1,2,4]$} & No differences \\
Performance & No differences & No differences & No differences &
\end{tabular}

Numbers in brackets indicate other groups that have significantl differing results.

design, manufacturing and administration technologies, and is at the top end of a continuum in AMT investment. Finally, designer companies make significan investments in design technologies; however, their investments in manufacturing and administrative-based AMT are at the same low level as traditionalist companies. A summary of the results showing relationships between the different variables analyzed and the four clusters can be found in Table 2 .

On the basis of this study, Jonsson (2000) studied a sample of 324 companies in the metal product processing sector in Sweden. The novelty in this case is that integration is utilized as one of the variables on which the taxonomy itself is constructed. Integration is measured through two factors: the degree of automation for data transaction between different manufacturing activities (for example, between product design and manufacture) and the degree of automation for data transaction between the various functional areas of the company (for example, between marketing and engineering, or between personnel and manufacturing). In a cluster analysis based on performance three groups of companies were distinguished; these were designated by the author as traditionalists, hard integrators and high investors. The traditionalist companies are those that present the lowest investments in the three types of AMT. Compared to the other two groups they show a particularly low degree of integration. The hard integrators account for the second highest mean values in investment and in degree of integration; in relative terms, their level of integration seems to be fairly high, even compared with the high investors. Their investments in administrative AMT are higher than in design or manufacturing. Lastly, high investor companies both make the largest investments in AMT and have the highest degree of integration, although the mean values for the variables (around four out of a maximum of seven) do not reflec exceptionally high investments in AMT. A summary of the results obtained can be found in Table 3 .

There appear to be clear similarities between the two taxonomies in some of the factors that our study takes into consideration (see Fig. 1), which is a reflec tion of the degree of correspondence in the two studies between the traditionalists and high investors on the one hand, and the generalist and hard integrator groups, on the other. The most obvious differentiating feature between the two groupings is the absence of a designer group in Jonsson's (2000) taxonomy. It should also be noted that, in the results of this latter study, a difference in performance can be appreciated between the different groups, with the high investors achieving the highest performance.

As previously stated, one of our aims is to identify possible similarities or differences between the groups that emerge in our study and those of previous works. As the plants in the population analyzed are, for the main part, small- or medium-sized, with many of them being quite small indeed, it would seem reasonable to assume that the groups define therein would not be the same as those observed in other studies which were based on samples of relatively large-sized companies. In Boyer et al. (1996), the sample is clearly biased towards larger plants (both in number of employees and sales). This was due in part to the decision to exclude very small plants (fewer than 50 employees) from the studies. Jonsson (2000) also excluded these plants (fewer than 50 employees) as not having the necessary resources to invest in AMT. In our opinion, the exclusion of plants of this type has at least two important effects. It must be taken into account that in many geographical areas it is the smallest factories 
Table 3

AMT investment taxonomy (from information in Jonsson, 2000)

\begin{tabular}{llll}
\hline & $(1)$ Traditionalists & $(2)$ Hard integrators & $(3)$ High investors \\
\hline Design & {$[2,3]$} & {$[1,3]$} & {$[1,2]$} \\
Manufacturing & {$[2,3]$} & {$[1,3]$} & {$[1,2]$} \\
Administrative & {$[2,3]$} & {$[1,3]$} & {$[1,2]$} \\
Integration & {$[2,3]$} & {$[1,3]$} & {$[1,2]$} \\
Size & {$[3]$} & {$[3]$} & {$[1,2]$} \\
Activity & No differences & No differences & No differences \\
Number of competitors & No differences & No differences & differences \\
Environmental uncertainty & No differences & No differences & No differences \\
Business strategy & & & {$[1]$} \\
$\quad$ Quality differentiation & {$[2,3]$} & {$[1]$} & {$[1]$} \\
Market differentiation & {$[2,3]$} & {$[1]$} & {$[1]$} \\
Delivery differentiation & {$[2,3]$} & No differences & {$[1]$} \\
Focus & {$[3]$} & {$[1]$} & No differences \\
Low price & No differences & {$[1]$} & {$[1]$} \\
Manufacturing capabilities & {$[2,3]$} & & {$[1]$} \\
Most infrastructure aspects & {$[2,3]$} & {$[1]$} & {$[1]$} \\
Maintenance management & & {$[1,3]$} & {$[1,2]$} \\
$\quad$ Preventive and soft & {$[2,3]$} & {$[3]$} & {$[1,2]$} \\
Hard & {$[3]$} & &
\end{tabular}

Numbers in brackets indicate other groups that have significantl differing results.

that most contribute to the creation of work and wealth in relative terms, and, as such, they should not be ignored in research. In Europe, for example, the percentage of manufacturing companies with fewer than 50 workers stands at $95.37 \%$ (Eurostat, 1999). ${ }^{2}$ Although these companies will clearly not be able to acquire certain high-cost AMT resources, we think it would be excessive to consider them unable to acquire other, much more affordable AMT. In fact, Swamidass and Kotha (1998) found that the positive relationship between size and advanced manufacturing technology depends on the AMT in question. The non-inclusion of these companies would therefore mean that it could not be demonstrated whether the smallest companies behave in different ways when investing in AMT, and also prevent other factors that might motivate said investments being discovered.

Once the different groups have been identified we shall try to provide new evidence on those aspects in which the results of Boyer et al. (1996) and Jonsson

\footnotetext{
${ }^{2}$ Statistical Offic of the European Communities. Latest available data.
}

(2000) differ from each other. We firs intend to discover whether a differentiated group of designer companies does in fact exist, as this would, in turn, suggest a differentiated technology strategy. Secondly, we shall try to fin out whether the different strategies of investment in AMT result in differences in investment performance. Finally, for our groupings we shall take into account some factors to which little consideration has been shown in other works, such as the effect of competitive priorities and a number of other factors that act as catalysts for investments.

\section{Working hypotheses}

The foregoing discussion of the literature leads us to the firs and second questions to be posed, which are, as outlined above, linked to the firs two objectives of our work: (1) Are there, as found in other sectors and geographical areas, different patterns of company AMT investment behavior in the Andalusian aeronautical sector? (2) What are the possible similarities with, or differences from, previous studies? 
To construct the taxonomy, we have followed the recommendations of various authors (Ketchen and Shook, 1996; Miller, 1996) about which variables should be used to obtain the groupings; these should be chosen carefully on the basis of existing theory and according to the type of study intended. In view of this, we decided to perform a cluster analysis taking into account only the investments made in the different types of AMT and with the premise that Andalusian aeronautical sector plants can be classifie into separate groups in accordance with their relative commitment to each type of AMT. We did not consider it appropriate to include integration as a variable for the construction of the taxonomy, as is proposed in the paper by Jonsson (2000). On the contrary, we decided to leave integration as an exogenous control variable, in line with Boyer et al. (1996), whose taxonomy is, in our opinion, clearer with respect to the patterns of investment obtained. Integration is, a priori, considered to be dependent upon the previously indicated variables and, from our point-of-view, its inclusion as yet another variable may distort the similarities between companies that enable the formation of groups that are already fairly well differentiated from each other by their investments in the various AMT options available.

To explain the reasons why the different groups are formed, we shall firs concentrate on the influ ence that might be exerted on investments by a number of explanatory factors: activity, size, competitive priorities, and information and catalyst elements; secondly, we shall analyze the differences that can be seen between integration, perceived difficultie and plant performance with respect to their investment patterns.

\subsection{Explanatory factors for AMT investment}

\subsubsection{Activity}

The aeronautical engineering industry, like the automobile or mechanical engineering sectors, has been characterized in several studies as a relatively intensive user of advanced manufacturing technologies (Twigg et al., 1992; Mansfield 1993; Schroder and Sohal, 1999). Although the manufacturing plants and companies studied fall generically within the same sector, we believe it is logical that certain relationships should be evident between the different types of AMT and the diverse industrial activities undertaken in the sector to which these technologies are applied.

It is observed that in most cases in the sector studied, at least one of the activities most related to fl xible automation is carried out, specificall engineering, machining and/or even assembly. It is worth remembering that there are other activities that are not susceptible to automation, such as sheet metal work.

In this context, the firs working hypothesis put forward is the following:

Hypothesis 1. A relationship exists between the industrial activity of a plant and its pattern of investments in AMT.

\subsubsection{Size}

There are numerous studies demonstrating the existence of a relationship between the size of a company and its use of technology (Romeo, 1975; Kelley and Brooks, 1991; Mansfield 1993; Dunne, 1994; Schroder and Sohal, 1999). Being largely made up of small-sized ancillary manufacturing units confers a series of characteristics upon the Andalusian aeronautical sector that could affect its capacity to make investments in AMT and its attitude towards them. Three of these features are the lack of sufficien finan cial resources (Machuca et al., 1995), the neglect of strategic management (Díez de Castro et al., 1995), and the personal characteristics of the CEO (Santos Cumplido, 2001).

However, as widely accepted as this relationship is, it is possible that this does not apply in the Andalusian aeronautical sector due to its specifi nature, and circumstances such as the overriding requirement to meet extremely highly specifie standards of quality and the very close working relationships with customers/suppliers, who often provide detailed instructions and supervision for production work. To this it should be added that several studies conducted in Spain suggest that, although company size is, in principle, a factor of influence since it conditions the availability of funds for investment, it does not seem to constitute a significan barrier to investment in AMT (Camisón Zornoza, 1994; Martínez Sánchez, 1996). As has been noted previously, Swamidass and Kotha (1998) obtain similar results which show that the type of AMT being considered had an effect on the positive relationship 
between size and use of advanced manufacturing technology.

For our part, we shall adopt the premise that the size of the plant is directly related to the use of technology, and so put forward the following hypothesis:

Hypothesis 2. A relationship exists between the size of a plant and its pattern of investments in AMT.

\subsubsection{Competitive priorities}

It is particularly intended that, as part of its third objective, our study should help supply new data to augment that provided by recent research (Banerjee, 2000) which points to a company's strategy having a possible influenc on its AMT investments due to the competitive priorities of cost, quality, delivery and fl xibility.

This relationship, which could not be clearly tested in the study conducted by Jonsson (2000), is a question that has received scant attention to date. On the one hand, one would think that plants that are more inclined towards fl xibility might be better disposed towards investment in fl xible technologies, compared with other firm which are more inclined towards cost reduction-although it is also true that AMT allow both cost reductions and increases in fl xibility thanks to the economies of scope. On the other hand, AMT-user companies might be more clearly inclined towards $\mathrm{fl}$ xibility in their procedures as a consequence of the improved fl xibility that AMT offer them.

In our study, we shall include these competitive priorities as an explanatory factor of investments made in AMT, assuming that the relationship analyzed is one where the strategy gives rise to the investment, but without excluding the possibility that one of the effects of a particular pattern of investments might be to change the direction of a company's competitive priorities. Our third working hypothesis is therefore the following:

Hypothesis 3. A relationship exists between the competitive operations priorities of a plant and its pattern of investments in AMT.

\subsubsection{Information elements}

A contribution intended from the third objective of our study is an analysis of any possible relationship between the level of investment made by plants and the information elements they have recourse to in order to fully inform themselves about current AMT. Information on AMT can be gathered from various sources (Langley and Truax, 1994): suppliers, consultants, government departments and agencies, trades fairs, journals, workers, and so on. Nevertheless, there are studies (Sun et al., 1997) that come to the conclusion that when a decision has to be made on a specifi proposal for AMT investment, not much attention is paid to some of these sources (books, conferences or government department-driven initiatives). This could lead us to believe that the probability of a specifi investment being made or not will in part depend on the sources used to gather information. Looking at it from another angle, it could also be argued that the companies with the highest levels of investment have made use of different information sources from those with lower levels of investment. This leads us to our fourth working hypothesis:

Hypothesis 4. A relationship exists between the information elements used by a plant and its pattern of investments in AMT.

\subsubsection{Catalyst elements}

Finally, we intend to consider a possible relationship between the level of investment in AMT and specifi catalyst elements that are present during the AMT adoption and implementation process. These catalyst elements are internal or external occurrences which explicitly trigger the consideration of new technologies. Amongst these could be a new strategic orientation (due to a change in owner or CEO, for example), the arrival of a new engineer, plans for expansion, a rise in profit or an injection of outside capital (Langley and Truax, 1994). Our fift working hypothesis is therefore:

Hypothesis 5. A relationship exists between a plant's catalyst elements and its pattern of investments in AMT.

\subsection{Effects of investments in AMT}

\subsubsection{Integration}

A priori, new technologies could be adopted either with a step-by-step approach or by imposing a radical 
change. The latter, however, involves greater risks; furthermore, in any organization there tends to be inertia, a resistance to changes in the status quo. This makes it advisable for a company to go along the road to integrated manufacturing progressively, with measured steps, making existing procedures for product design and manufacture their starting point. In fact, there are authors who believe that a company's adoption of the CIM concept should be part of a radical change in the company's conception of its business - following the business process redesign (BPR) approach - and even these consider that, when it comes to the implementation of such radical change, this should be done gradually (Liu and Chen, 1998). Such recommendations could be due to research finding that suggest that the more radical the change, the more limited are the perceptions of those involved of the resulting benefit (Shepherd et al., 2000).

In short, it may safely be concluded that, since a company must have reached a certain technological level before it can consider that it should be combined in an integrated system, a minimum level of existing use of AMT would appear to be a necessary prerequisite for the integration of activities (Boyer et al., 1996; Nagalingam and Lin, 1999). Furthermore, one of the results that can be expected of higher levels of investment in AMT is a greater degree of integration between activities. From these expectations emerges our sixth working hypothesis:

Hypothesis 6. A relationship exists between a company's pattern of AMT investments and the degree of integration of its production activities.

\subsubsection{Performance}

When it comes to describing the many actual and potential benefit and advantages that AMT offers, the literature can be grouped into different categories. Thus, for example, McDermott and Stock (1999) distinguish between operational benefit (that bring improvements in productivity and fl xibility), organizational benefit (that include improvements in work-fl $\mathrm{w}$, communication, integration and management control), and competitive benefit (where improvements in sales growth, market share or the return on investment could be sought). Nevertheless, the criterion usually adopted seems to involve differentiation between those benefit that would fall within the framework of company strategies and those that have come to be designated as operational, even though the latter will surely be reflecte in the former and therefore in the overall performance of the manufacturing plant.

Research conducted to date on patterns of investment and company performance shows results that, a priori at least, seem to point in opposite directions. Boyer et al. (1996) observed that there were no differences in performance on the basis of the each company's investment pattern, which is in line with results obtained by other authors that indicate that the use of AMT does not have any direct impact on a company's performance (Swamidass and Kotha, 1998). Jonsson (2000), for his part, did note differences in performance between the different groups, with the high investors being those who displayed greater performance. This is in line with results obtained by other authors who noted a higher performance from those companies with greater investment in advanced manufacturing technologies (Gordon and Sohal, 2001). In the light of such diverse premises and results, we put our fina hypothesis in the following limited terms:

Hypothesis 7. A relationship exists between a plant's pattern of investments in AMT and its performance.

\subsubsection{Difficultie}

The various problems associated with the implementation of advanced manufacturing technologies (Babbar and Rai, 1990; Boer et al., 1990; Gerwin and Kolodny, 1992; Aggarwal, 1995; Sohal, 1997) have thus far been classifie into two inter-related types (Naik and Chakravarty, 1992; Kaighobadi and Venkatesh, 1994): technical problems and management problems. This distinction could easily be extended to the different types of AMT, as long as it is borne in mind that the more complex the technologies installed, the greater the problems that might occur. As far as technical problems are concerned, it is thought that these are due to the complexity of the technology per se, and the technical and analytical decisions that have to be taken when advanced manufacturing systems are introduced. The main management problems that are highlighted given the complexity of implementation are the management's resistance to change and the complex infrastructure 
the systems require. Fortunately, not all the possible costs and inconveniences that the implementation of AMT could, a priori, involve have to be faced when making investments. This will logically depend on each specifi case and the circumstances of the company in question. Sun et al. (1997) point out that the reason for this could be attributed to the previous experience a company has had in this type of investment, and this stands out as one of the crucial factors for success. Assuming that the differences we expect to detect between the groups in the population under analysis will depend on their level of investment in AMT, and that this will be reflecte in the level of complexity of the equipment and the specifi experience had by each factory, our last working hypothesis is as follows:

Hypothesis 8. A relationship exists between the difficultie observed by a plant and its pattern of investments in AMT.

\section{Methodology}

\subsection{Sample and data gathering}

As already indicated, the target population is made up of manufacturing plants operating in the Andalusian aeronautical sector. In total, there are 3 plants belonging to the CASA group, and 17 small- and medium-sized ancillary companies. In view of this low number, we decided to conduct a comprehensive analysis of the sector and study the entire population.

With regard to data gathering, it must be taken into account that this specifi study is encompassed within a wider research project on the adoption and implementation of AMT in the Andalusian aeronautical sector. Given that the relatively wide scope of such a project would require the use of quite long questionnaires, it was decided to break the study into two parts in order to avoid the likely initial respondent resistance to a single, excessively-long questionnaire. The basic objective of the firs part of the questionnaire was to determine the types and extent of AMT use in the sector, and a postal survey was used for this purpose. Our starting point for its design was a preliminary draft made after a detailed study of similar questionnaires used in empirical studies of this type
(Miller and Roth, 1994; Mechling et al., 1995; Small and Chen, 1995; Boyer et al., 1996; Milling, 1997). This preliminary version was submitted to successive tests by researchers not involved in the study, with a view to improving the questions and their wording. A pilot survey involving three companies from the population was then conducted to test the resulting questionnaire. The definit ve questionnaire was mailed to all plants in the population on 23 July 1999. The collation of responses was completed on 10 March 2000; this prolonged delay would have been even greater if not for the perseverance shown in follow-up telephone work. This not inconsiderable effort enabled both a $100 \%$ response rate to eventually be achieved, and also doubts that had arisen in some plants about some of the questions to be clarified thus contributing to an increase in the reliability of the data obtained.

Armed with knowledge of the AMT to be found in each plant, a second questionnaire was devised following a process similar to that used for the first The aim was to obtain data on the investment adoption and implementation process, and to determine, in relative terms, the performance of the plants analyzed in the population. It was decided to conduct personal interviews for the completion of the questionnaire in order to avoid another long wait for the survey responses to be collated and further possible problems of interpretation, both of which were real possibilities given the relative complexity of the second questionnaire. This decision was facilitated by the relatively small number of interviews that would be required (20). The second questionnaire was mailed on 24 January 2001 so that respondents could familiarize themselves with its content well before the interview. On this occasion, the process of data gathering took less than 3 months.

The average duration of the interviews was $2 \mathrm{~h}$, somewhat longer than was initially estimated. This was due to various other matters not specifie in the questionnaire being dealt with during the course of the interview. The related matters that arose out of the conversations were useful insofar as they allowed us to gain a deeper insight into unforeseen aspects of the topic. As for questions included in the second questionnaire directly related to this paper, two examples would be the main objectives or benefit expected and which had motivated the investments, and the extent to which some factors had hampered the AMT adoption and implementation process (a lack of skilled 
workers, the reorganization of the workplace, and so on).

In most of the smaller auxiliary companies, it was the managing director and owner who completed both questionnaires, an advantage that cannot usually be guaranteed in this type of study when mail is the only means of contact. As for the larger plants, it was the head or assistant head of engineering who fille out the firs questionnaire and attended the interviews.

Another point to be emphasized is that the information obtained from the firs questionnaire was reviewed at the start of each interview with two aims: firstl, to determine how the investments being evaluated had developed since the plants had responded to the firs questionnaire; and secondly, to detect any possible errors and omissions in the responses. As a consequence, some had to be corrected. This fact is indicative of the risks associated with studies based on postal question- naires: the accuracy and reliability of the data gathered is extremely dependent on the attention given by the respondents and on their correct interpretation or understanding of the questions posed. As this experience demonstrates, this is often not the case.

\subsection{Measurement scales}

Activity, plant size, information and catalyst elements, and difficultie observed during the adoption and implementation process were measured on unidimensional scales. Given that one of the possible effects of investing in AMT that can be predicted might be a variation in the size of the work-force, we preferred to estimate the company size variable on the basis of annual sales volumes. Each information or catalyst element and each difficult was independently measured on a Likert scale of seven points (see Table 4).

Table 4

Information and catalyst elements: indicators and scales of measurement

\begin{tabular}{|c|c|c|c|c|c|c|c|}
\hline & \multicolumn{7}{|c|}{ Measurement scale } \\
\hline & \multicolumn{7}{|c|}{$\begin{array}{l}\text { How great an importance do you think the following factors have had in determining } \\
\text { your investments in AMT? }\end{array}$} \\
\hline & \multicolumn{2}{|c|}{ No importance } & \multicolumn{3}{|c|}{ Medium importance } & \multicolumn{2}{|c|}{ Maximum importance } \\
\hline \multicolumn{8}{|l|}{ Information elements } \\
\hline Information from suppliers & 1 & 2 & 3 & 4 & 5 & 6 & 7 \\
\hline Information from workers & 1 & 2 & 3 & 4 & 5 & 6 & 7 \\
\hline Other companies & 1 & 2 & 3 & 4 & 5 & 6 & 7 \\
\hline Trades Fairs & 1 & 2 & 3 & 4 & 5 & 6 & 7 \\
\hline Journals and Magazines & 1 & 2 & 3 & 4 & 5 & 6 & 7 \\
\hline Government Departments and Agencies & 1 & 2 & 3 & 4 & 5 & 6 & 7 \\
\hline \multicolumn{8}{|l|}{ Catalyst elements } \\
\hline Arrival of new employee/executive & 1 & 2 & 3 & 4 & 5 & 6 & 7 \\
\hline Plans for Expansion & 1 & 2 & 3 & 4 & 5 & 6 & 7 \\
\hline Rising profit & 1 & 2 & 3 & 4 & 5 & 6 & 7 \\
\hline Injection of outside capital & 1 & 2 & 3 & 4 & 5 & 6 & 7 \\
\hline \multirow[t]{3}{*}{ Existence of skilled labor } & 1 & 2 & 3 & 4 & 5 & 6 & 7 \\
\hline & \multicolumn{7}{|c|}{$\begin{array}{l}\text { To what degree do you think the following factors have had an adverse effect } \\
\text { on the adoption and implementation process of your investments in AMT? }\end{array}$} \\
\hline & & icult & & di & & & ifficult \\
\hline \multicolumn{8}{|l|}{ Difficultie } \\
\hline Lack of skilled labor & 1 & 2 & 3 & 4 & 5 & 6 & 7 \\
\hline Loss of fl xibility & 1 & 2 & 3 & 4 & 5 & 6 & 7 \\
\hline Equipment breaking down & 1 & 2 & 3 & 4 & 5 & 6 & 7 \\
\hline Re-organization of Depts. & 1 & 2 & 3 & 4 & 5 & 6 & 7 \\
\hline Reticence amongst employees & 1 & 2 & 3 & 4 & 5 & 6 & 7 \\
\hline Reticence amongst executives & 1 & 2 & 3 & 4 & 5 & 6 & 7 \\
\hline Difficultie with evaluation & 1 & 2 & 3 & 4 & 5 & 6 & 7 \\
\hline Difficultie with performance measurement & 1 & 2 & 3 & 4 & 5 & 6 & 7 \\
\hline Difficultie with financin & 1 & 2 & 3 & 4 & 5 & 6 & 7 \\
\hline
\end{tabular}


The rest of the factors considered were measured on multidimensional scales. For the development and validation of scales, various recommendations provided in literature in recent years were taken into account, such as the utilization of sub-constructs or the utilization of scales previously validated in other research (Malhotra and Grover, 1998; O'Leary-Kelly and Vokurka, 1998; Hensley, 1999). This latter factor was responsible for the decision to opt in almost all cases for a Likert seven-point measurement scale, since this is the scale that is habitually applied in OM research surveys. However, in the operations field only a small number of other scales have so far been developed. The scales utilized in our research were adopted from other studies, with slight adaptations in some cases. This led us to expect, a priori, high levels of inter-item reliability; on the other hand, all the scales can be assumed to be new if we consider that they have never before been applied exclusively to companies in the aeronautical sector, and this could imply less reliability than expected. As described later, after the corresponding reliability test it was necessary to modify one of the scales.

To measure the inter-item reliability of the scales we employed Cronbach's $\alpha$, which is clearly the most extensively used. As is known, this coefficien can take values between 0 and 1 , and the higher the coefficient the higher the reliability. No general agreement seems to exist with regard to the value the coefficien should have for it to be considered acceptable (O'Leary-Kelly and Vokurka, 1998, p. 397); proposals have been found ranging from 0.4 (Van de Ven and Ferry, 1980) to 0.7 (Nunnally, 1978). However, a different level is usually required depending on whether the scale to be assessed is already well established $(0.7)$ or has been newly developed (0.6) (Nunnally, 1978; Flynn et al., 1990; Hair et al., 1999).

As regards the validity of the scales utilized, that is, whether the scales effectively measure the concepts that they are intended to measure and no others, this was gauged by means of content validity. As it is impossible to evaluate this aspect with statistical tools (Hoskisson et al., 1993, p. 217), expert judgement or references in literature have to be relied upon to determine whether the scale in question truly measures the concept or construct for which it was developed. This measurement is therefore by nature subjective and, as such, will always be debatable. As recom- mended by various authors, in our research, content validity was checked by employing previously developed scales (Flynn et al., 1990; Malhotra and Grover, 1998; Hensley, 1999) that in some cases were adapted on the basis of a rigorous bibliographical review and the opinion of more than a dozen researchers and university teachers.

Although a high level of reliability is a necessary but not sufficien condition to ensure the validity of a research survey, we consider that by employing scales previously validated in other studies and by obtaining very high indicators of their reliability in our population, they are sufficien to ensure an acceptable level of validity.

\subsubsection{Investment in AMT}

Since the development of a taxonomy is not intended to defin ideal types, but rather to classify the organizations studied into comprehensive and mutually exclusive groups, the choice of the variables used to establish the classificatio is a decision of crucial importance that should be made on the basis of existing theory and the nature of the research study to be conducted (Ketchen and Shook, 1996; Miller, 1996). Many classification can be found in literature on AMT, although they all reflec a high degree of similarity. The criterion most widely applied for the categorization of AMT is based on the function or type of activity that the technology performs. Three basic categories of advanced automation can be distinguished: that used in design/engineering, that used in manufacturing and that used for the administrative tasks of planning and control. The origin of this classificatio can be found in Meredith (1987), with subsequent modification along similar lines by other authors. Boyer et al. (1996) compiled a list of the various classification that have appeared in literature which we have taken as the basis for Table 5, where the various types of technology are arranged in columns and authors in rows. As can be observed, AGV and AS/RS do not explicitly appear in Table 5 . The reason for this is that both technologies are included in the more generic term of AMHS, since some of the studies included in this table do not make a distinction between the two. Nevertheless, in the studies by Lei and Goldhar (1991), Gerwin and Kolodny (1992), Machuca et al. (1995), and Cohen and Apte (1997), the two technologies are referred to separately, in the 
Table 5

A number of existing classification for AMT

\begin{tabular}{|c|c|c|c|c|c|c|c|c|c|c|c|c|c|c|c|c|c|}
\hline & \multicolumn{4}{|c|}{ Design } & \multicolumn{7}{|c|}{ Manufacturing } & \multicolumn{6}{|c|}{ Planning } \\
\hline & CAD & CAE & CAPP & GT & CAM & $\mathrm{NC}$ & $\mathrm{CNC}$ & $\mathrm{RP}$ & AMHS & FMS & $\overline{\mathrm{CAI}}$ & MRP & MRPII & JIT & CPM & $\mathrm{ABC}$ & $\overline{\mathrm{SFC}}$ \\
\hline $\begin{array}{l}\text { Rosenthal (1984) } \\
\text { CAD } \\
\text { CAD/CAM } \\
\text { CAM } \\
\text { Factory management and control }\end{array}$ & $*$ & & & & $*$ & & $*$ & $*$ & $*$ & $*$ & & $*$ & & & & & $*$ \\
\hline $\begin{array}{l}\text { Meredith (1987) } \\
\text { Engineering techniques } \\
\text { Manufacturing techniques } \\
\text { Business techniques }\end{array}$ & $*$ & $*$ & $*$ & $\begin{array}{l}* \\
* \\
*\end{array}$ & * & & $*$ & $*$ & * & $*$ & & * & & * & & & \\
\hline $\begin{array}{l}\text { Adler (1988) } \\
\text { Design automation } \\
\text { Manufacturing automation } \\
\text { Administrative automation }\end{array}$ & $*$ & $*$ & & & $*$ & & $*$ & & $*$ & & & $*$ & * & & & $*$ & $*$ \\
\hline $\begin{array}{l}\text { Lei and Goldhar (1991) } \\
\text { CAD } \\
\text { CAM } \\
\text { Planning }\end{array}$ & $*$ & * & $*$ & & $*$ & & $*$ & & $*$ & & & $*$ & * & & & & * \\
\hline $\begin{array}{l}\text { Saraph and Sebastian (1992) } \\
\text { Process technologies } \\
\text { Planning systems }\end{array}$ & $*$ & & & $*$ & & & $*$ & & $*$ & & & * & * & $*$ & & & \\
\hline $\begin{array}{l}\text { Gerwin and Kolodny (1992) } \\
\text { Product and process design } \\
\text { Manufacturing planning and control } \\
\text { CAM }\end{array}$ & * & * & * & * & & $*$ & $*$ & $*$ & $*$ & $*$ & $*$ & $*$ & & & * & & \\
\hline $\begin{array}{l}\text { Machuca et al. (1995) } \\
\text { Shop-floo automation } \\
\text { Engineering automation } \\
\text { Planning and control automation }\end{array}$ & $*$ & * & $*$ & & * & $*$ & $*$ & $*$ & $*$ & $*$ & & $*$ & * & & & & $*$ \\
\hline $\begin{array}{l}\text { Cohen and Apte (1997) } \\
\text { Design } \\
\text { Programmable automation } \\
\text { technologies for fabrication } \\
\text { Infrastructure technologies } \\
\text { Planning and programming }\end{array}$ & * & & * & * & $*$ & $*$ & $*$ & $*$ & $*$ & $*$ & & & * & & & & * \\
\hline $\begin{array}{l}\text { Swamidass and Kotha (1998) } \\
\text { Product design technologies } \\
\text { Process technologies } \\
\text { Logistics/planning technologies }\end{array}$ & $*$ & * & & & $*$ & $*$ & $*$ & $*$ & * & $*$ & $*$ & * & $*$ & & & & $*$ \\
\hline
\end{tabular}

From Boyer et al. (1996, p. 300), modifie and extended. 
same way they have been analyzed in the present study. This means that a distinction has been made between $\mathrm{AGV}$ and $\mathrm{AS} / \mathrm{RS}$ in the analysis, even though they appear as one in Table 5 under the acronym of AMHS, as separate information is not available for each in all the sources used.

None of the classification consulted have been exclusively adhered to for determining the types of technology in the firs column of the table; rather, an ad hoc compilation and synthesis has been made (Adler, 1988; Starr, 1989; Fine, 1990; Aquilano and Chase, 1991; Gerwin and Kolodny, 1992; Álvarez Gil, 1993; Vanderspek, 1993; Machuca et al., 1995; Small and Chen, 1995; Boyer et al., 1996; Krajewski and Ritzman, 1996; Cohen and Apte, 1997; Swamidass and Kotha, 1998). In this way, we have tried to produce the most complete and descriptive taxonomy possible, one which would serve as a basis for the measurement scale for investments in AMT and for the construction of our firs questionnaire. Other technologies such as e-mail or EDI that are taken into account by other authors (Boyer et al., 1996) have not been included, as these were not strictly considered to be manufacturing technologies. MRP was also excluded after data analysis confirme that it has been completely replaced by MRPII in the Andalusian aeronautical sector.

With regard to the method used for measuring these investments, what is usually done in similar studies is that the persons surveyed respond on a Likert scale of seven points depending on the level or intensity of the investments made by their company in each technology (there are, however, studies which measure investment much more simply, for example, in Small and Yasin (1997)). There are several reasons why we decided against such an option in this case. The responses thus obtained suffer from a markedly subjective character, although this disadvantage seems to be taken as the lesser of two evils in existing empirical studies on the topic. In our opinion, this disadvantage could be exacerbated in a study such as ours, where the population is so small and includes a high proportion of smaller companies that, a priori, were not expected to be over-familiar with these types of technology, and where there could also be great disagreement between one company and another on what might be considered a 'large' or 'small' investment. Moreover, in the overall framework of objectives for the research program within which the present study is encompassed, and in the specifi case of manufacturing AMTs, it was not sufficien to clarify whether the plants considered their investments to be small, medium or large; we needed to know the number of machines and systems installed in each case. Consequently, a dichotomous variable was utilized for each technology that expressed either the existence (1) or absence (0) of each type of technology in a plant.

In the specifi case of manufacturing AMTs, the plants not only indicated the presence of the technology in question, but also the number of items of equipment installed in the plant. We thought this fact should be included in the measurement as the intensity of investments would obviously differ greatly depending on the number of items of equipment installed compared with the rest of the plants. This was added to the scale by incorporating the quotient of the number of items installed in the plant and the total number of items of equipment installed in the entire sector to the 1 that represented the existence of the technology (if this was the case). To give an example: if a plant in the population were to have amongst its manufacturing equipment 2 CAM systems, $7 \mathrm{CNC}$ systems and 3 CAI systems, whilst the total number of items of equipment of these three types of AMT for the entire population were 90,103 and 16 , respectively, the score awarded to the factory in question would be: $\mathrm{AMTF}=(1+2 / 90)+(1+7 / 103)+(1+3 / 16)=$ $1.02+1.07+1.19=3.28$.

Each company is given a total score for each type of AMT (design, manufacture and planning). In the remainder of the paper, these three variables will be referred to as AMTD, AMTF and AMTP. It is important to highlight that one of the consequences of this is that graduation of the measurement scales varies depending on the type of AMT. This has to be taken into account both when comparing mean values and, when conducting the cluster analysis. After measuring the reliability of the scales, none of the items had to be eliminated since, as can be seen in Table 6, Cronbach's $\alpha$ is above the reference value of 0.7 in all three cases.

\subsubsection{Competitive priorities}

The indicators adopted in the case of competitive priorities are shown in Table 7. Almost all of these had been identifie in previous studies (Corbett, 1996; Roth, 1996; Boyer and McDermott, 1999; Avella Camarero and Fernández Sánchez, 2000; Boyer and 
Table 6

AMT investments: scales and reliability coefficient

\begin{tabular}{|c|c|c|c|}
\hline & Technology & Mean & S.D. \\
\hline \multirow[t]{4}{*}{ Design (AMTD) $(\alpha=0.7135)$} & Computer-aided design (CAD) & 0.70 & 0.47 \\
\hline & Computer-aided engineering (CAE) & 0.45 & 0.51 \\
\hline & Computer-aided process planning (CAPP) & 0.30 & 0.47 \\
\hline & Group technology (GT) & 0.30 & 0.47 \\
\hline Scale & & 1.75 & 1.41 \\
\hline \multirow[t]{8}{*}{ Manufacturing (AMTF) $(\alpha=0.8098)$} & Computer-aided manufacturing (CAM) & 0.65 & 0.56 \\
\hline & Numerical control (NC) & 0.10 & 0.45 \\
\hline & Computer numerical control $(\mathrm{CNC})$ & 0.60 & 0.56 \\
\hline & Robotics (PR) & 0.00 & 0.00 \\
\hline & Automated guided vehicles (AGV) & 0.15 & 0.46 \\
\hline & Automated storage/retrieval systems (AS/RS) & 0.10 & 0.45 \\
\hline & Flexible manufacturing systems (FMS) & 0.10 & 0.45 \\
\hline & Computer-aided inspection (CAI) & 0.45 & 0.57 \\
\hline Scale & & 2.15 & 2.46 \\
\hline \multirow[t]{5}{*}{ Planning (AMTP) $(\alpha=0.8105)$} & Manufacturing resource planning (MRPII) & 0.35 & 0.49 \\
\hline & Just in time (JIT) & 0.00 & 0.00 \\
\hline & Computerized preventive maintenance (CPM) & 0.15 & 0.37 \\
\hline & Activity-based costing (ABC) & 0.15 & 0.37 \\
\hline & Shop-floo control (SFC) & 0.20 & 0.41 \\
\hline Scale & & 0.85 & 1.39 \\
\hline
\end{tabular}

Pagell, 2000; Ward and Duray, 2000). The only exception is the item "to establish a culture of quality", the inclusion of which has been considered appropriate given the importance that is attached to this objective in the sector under study. The importance given to each of the objectives has been measured on a Likert scale of seven points $(1=$ not important; $4=$ important; $7=$ critically important).

On calculating Cronbach's $\alpha$ for the scale that was initially proposed, we discovered that in this case the values obtained would not guarantee an acceptable level of reliability. The values of the indicator

Table 7

Operations competitive priorities: scales and reliability coefficient

\begin{tabular}{llll}
\hline & Objective & Mean & S.D. \\
\hline Cost $(\alpha=0.7353)$ & Reduce inventory & 2.90 & 1.94 \\
& Reduce production costs & 5.80 & 5.55 \\
Scale & Increase labor productivity & 4.75 & 1.05 \\
Quality $(\alpha=0.6929)$ & & 6.35 & 0.25 \\
& Consistent quality with low defect rate & 6.30 & 0.49 \\
Scale & Supply of reliable products & 6.55 & 0.98 \\
Delivery & Establish a culture of quality & 6.40 & 0.60 \\
Flexibility $(\alpha=0.6799)$ & & 6.50 & 0.57 \\
& Meet promised delivery dates & 5.30 & 0.69 \\
& Fast introduction of new products & 4.95 & 1.49 \\
Scale & Adjust capacity quickly & 4.95 & 1.39 \\
& Fast changes in volume & 4.20 & 2.23 \\
\end{tabular}


Table 8

Integration: scale and reliability coefficien

\begin{tabular}{llrr}
\hline & Connections & Mean & S.D. \\
\hline Integration $(\alpha=0.8994)$ & Between product design and process planning & 3.05 & 2.70 \\
& Between product design and manufacturing & 3.90 & 2.92 \\
& Between product design and production planning & 2.40 & 2.41 \\
& Between process planning and manufacturing & 3.10 & 2.79 \\
& Between production planning and manufacturing & 2.50 & 2.46 \\
Scale & Between various items of manufacturing equipment & 2.15 & 1.87 \\
\hline
\end{tabular}

of inter-item reliability that are shown in Table 7 are those obtained after eliminating items that prevented an adequate level of reliability being achieved.

Regarding the reliability of the deliveries subconstruct, the value obtained for Cronbach's $\alpha$ on the scale proposed, which included a second item (fast deliveries), was very low (0.1236). A qualitative analysis of the responses obtained in the interviews showed that while the objective of deliveries was important for some of the companies in the sector, it was not a priority objective for competitiveness for any of the companies. In addition, in a sector in which manufacture requires considerable periods of time, and where most of the work is under contract, a reduction in manufacture times in order to achieve faster deliveries seems to be much less important than complying with promised delivery dates; this is what seems to be suggested by the mean and standard deviation obtained for the two items (the objective fast deliveries obtained a lower mean (5.19) and a higher standard deviation (1.39) than the objective deliveries on time ( 6.5 and 0.69 , respectively)). For this reason, it was decided to measure the deliveries objective on a mono-dimensional scale that exclusively analyzes the importance of meeting promised delivery dates.

\subsubsection{Integration}

The degree of integration has been measured by the extent to which partial transactions between activities are computerized. All possible partial integration taken into consideration is shown in Table 8 and has been measured on a seven-point Likert scale $(1=$ not integrated $(0 \%) ; 4=$ semi-integrated $(50 \%) ; 7=$ fully integrated $(100 \%))$. The source of this scale is Dean et al. (1992), and it has been utilized in subsequent studies in the same way as it is here (Boyer et al., 1996; Milling, 1997; Jonsson, 2000).

\subsubsection{Performance}

We have approached the measurement of performance through four indicators, two related to growth (market share and sales) and two to profit (ROI and ROS); the validity of these indicators is supported by previous empirical studies (Boyer et al., 1996, 1997; Gupta et al., 1997; Ward and Duray, 2000). For each indicator, the measurement considered the position of the company in relation to its competitors over the past 3 years on a seven-point Likert scale $(1=$ significantl worse; $4=$ similar; $7=$ significantl better). None of the items had to be eliminated from the scale, as the value of Cronbach's $\alpha$ was notably higher than 0.7 in both cases (see Table 9).

\subsection{Data analysis}

A cluster analysis was conducted using Ward's hierarchical method of minimum variance (Everitt, 1981), based on the values of the AMTD, AMTF and AMTP variables. The objective was to test our proposition as to whether the plants in the Andalusian aeronautical sector can be classifie into distinct groups according to their relative commitment to each type of AMT, that is, whether an AMT investment patterns taxonomy can

Table 9

Performance: scales and reliability coefficient

\begin{tabular}{llll}
\hline & Objectives & Mean & S.D. \\
\hline Growth $(\alpha=0.8645)$ & Market share growth & 5.15 & 1.31 \\
& Sales growth & 5.45 & 1.19 \\
Scale & & 5.30 & 1.17 \\
Profi $(\alpha=0.9596)$ & Return on investment & 4.95 & 1.08 \\
& (ROI) & & \\
Scale & Return on sales (ROS) & 4.74 & 1.04 \\
& & 4.84 & 1.04 \\
\hline
\end{tabular}


be established. These values have been typifie in order to minimize any influenc that the different scales used for each variable might have.

To test Hypothesis 1, which deals with the relationship between company activity - a qualitative variable - and patterns of investment, we have made use of Fisher's exact test (Ruiz-Maya, 1995). The rest of the proposed hypotheses have been tested by one-way ANOVAs and the corresponding multiple comparison least significan difference (LSD) test ${ }^{3}$ that allows any possible differences detected to be observed by pairs of treatments.

We feel it is important to point out that all these statistical tests take into account the size of the sample being analyzed when determining the significanc of the contrast, which means they are no less valid for having been calculated on the basis of a relatively small number of elements. In the specifi case of the cluster analysis, it must not be forgotten that this is an objective method that quantifie the structural features of a whole range of observations, and not a statistical inference technique that analyzes the extent to which the parameters of a sample could be representative of a population (Hair et al., 1999). The SPSS 10.0 statistical program was used for data analysis.

\section{Results and discussion}

\subsection{Investment patterns identifie in the sector}

As previously stated, a cluster analysis was performed. One of the key aspects of cluster analyzes is to determine the appropriate number of groups; the aim is to balance parsimony (the fewer the groups the better for comparisons and for drawing definit conclusions) and accuracy (which should increase in accordance with the number of groups). Other studies employing this type of analysis, such as the previously referred to work by Boyer et al. (1996), make use of certain ground rules, such as those proposed by Lehmann (1979) and Milligan and Cooper (1985), to decide upon an appropriate number of clusters

\footnotetext{
3 This is simply a $t$-test on various pairs of treatments. Instead of calculating $s^{2}$ for each pair of treatments, the error mean square from the ANOVA table is used as an overall mean value (SPSS algorithms).
}

depending on the number of elements in the sample. In our case, given the relatively few companies surveyed, such rules are clearly inapplicable. This does not represent a serious disadvantage insofar as the basic criterion for the grouping is that the result obtained may be interpreted in the light of the problem posed. In fact, existing theories (Woodward, 1965; Wheelwright and Hayes, 1985) establish that a good taxonomy should be relatively unaffected by the technique or the sample used to construct it; it may even be based on mere observation, as its powers of description can still be very considerable (Miller, 1996).

With this in mind, the cluster analysis enables three groups of plants to be clearly differentiated on the basis of their investments in AMT, as can be seen in the dendrogram in Fig. 2. In short, it can be stated that cluster membership is assessed by calculating the total sum of squared deviations from the mean of a cluster. The criterion for fusion is that it should produce the smallest possible increase in the error sum of squares. Ward's minimum variance method has been applied to the typifie values obtained for each variable in order to prevent the differences in the scales used to measure AMTD, AMTF and AMTP distorting the relative distances between the means.

Having identifie these three groups, a one-way ANOVA was carried out to check that the differences between them were significant the results of these tests and the means for the three variables (AMTD, AMTF and AMTP) in each group, are presented in Table 10. For a more detailed analysis of the differences found between the means for pairs of clusters, a multiple comparison LSD test was performed. The results of this test have also been incorporated in Table 10. For each group, the other group or groups for which the differences presented are significan for $P<0.05$, are indicated in brackets.

From the results obtained it is possible to distinguish three clusters, each of which contains a set of plants which we have designated traditionalists (cluster 1), designers (cluster 2) and investors (cluster 3) on the basis of their investments in each type of AMT and their differences from the plants included in the other two groups:

(1) Traditionalists: This cluster groups a total of nine plants ( $45 \%$ of the population) that base their manufacturing activities on traditional technologies. 


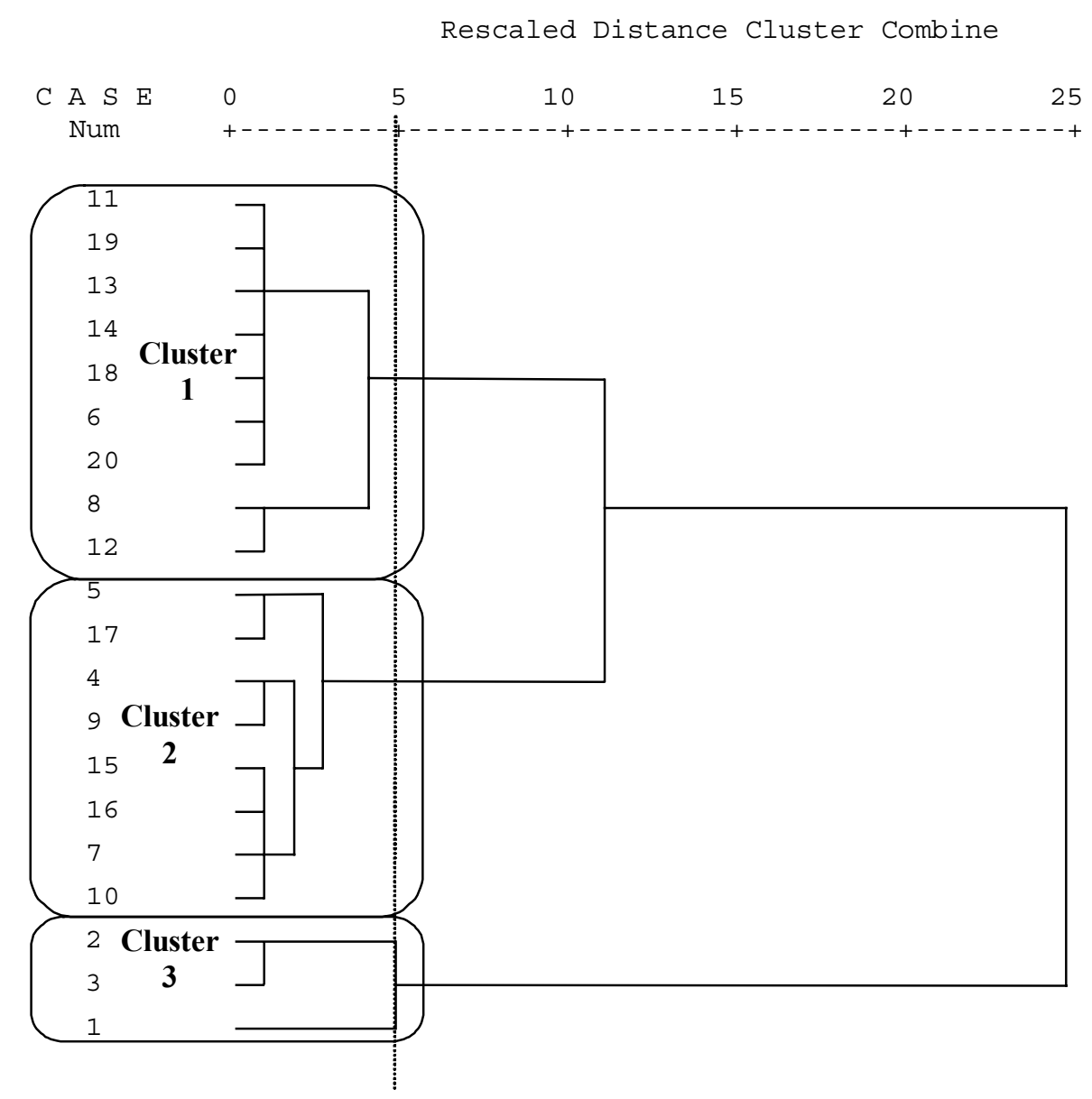

Fig. 2. Ward's minimum variance cluster method: dendrogram.

Table 10

AMT investments by group: results of ANOVA and LSD test

\begin{tabular}{cllll}
\hline & $\begin{array}{l}\text { Traditionalists } \\
(\text { cluster } 1, n=9)\end{array}$ & $\begin{array}{l}\text { Designers } \\
\text { (cluster } 2, n=8)\end{array}$ & $\begin{array}{l}\text { Investors } \\
\text { (cluster 3, } n=3)\end{array}$ & ANOVA \\
\hline AMTD & {$[2,3]$} & {$[1]$} & {$[1]$} & $F=28.113$ \\
Mean & 0.44 & 2.62 & 3.33 & $P<\mathbf{0 . 0 0 1}$ \\
S.D. & 0.53 & 0.92 & 0.58 & $F=11.065$ \\
AMTF & {$[3]$} & {$[3]$} & {$[1,2]$} & $P<\mathbf{0 . 0 0 1}$ \\
Mean & 0.81 & 2.15 & 6.18 & 3.87 \\
S.D. & 0.14 & 1.16 & {$[1,2]$} & $F=28.534$ \\
AMTP & {$[3]$} & {$[3]$} & 3.66 & $P<\mathbf{0 . 0 0 1}$ \\
Mean & 0.44 & 0.25 & 0.58 & \\
S.D. & 0.88 & 0.46 & & \\
\hline
\end{tabular}

Numbers in brackets indicate other groups significantl different from the cluster in the multiple comparison LSD test $(P<0.05)$. The differences in the scales used to measure the AMTD, AMTF and AMTP variables must be taken into account to correctly interpret and compare the means (see Section 4.2). 
Their investments in any of the three types of AMT stand at a very low level and in every case fall below the mean for the sector. Although in the case of planning AMTs the mean of their investments $(0.44)$ is somewhat higher than in the designers $(0.25)$ group, this difference is not significant

(2) Designers: This cluster comprises eight companies $(40 \%$ of the population) with high investments in design AMTs. Although their mean level of AMTD (2.62) is lower than that of the investor plants (3.33), this difference is not significant However, their investments in both manufacture and planning AMTs are at a similar low level to that of the traditionalists, to the extent that significan differences in these variables cannot be appreciated between them. Although their AMTF mean (2.15) is higher than that of the traditionalists (0.81), the wide standard deviations of the two groups detract from the significanc of the differences. It may be concluded therefore that this group identifie those plants inclined towards design AMTs.

(3) Investors: This is the smallest group identified with only three plants ( $15 \%$ of the population), those which correspond to CASA. These have the greatest mean investments in all three types of AMT, clearly surpassing the mean for the sector as a whole, although, as previously indicated, the difference from the designers in the level of AMTD does not reach a significan level.

Given the differences in the measurement scales utilized and in the variables taken into account to construct the different taxonomies, we tentatively believe that certain similarities can be observed between the different groups in the Andalusian aeronautical sector and those found in the previous studies on our approach to the analysis of the question in hand was based. The firs similarity can be found in the traditionalist group. In all respects, this seems to be identifiabl with similarly-designated groups in Boyer et al. (1996) and Jonsson (2000). With regard to this latter study, although our grouping does not take account the integration variable, it should be noted that the traditionalist group is characterized by a low level of investment in all three types of AMT. The result is that the degree of integration is, as we shall see later, also very low (a characteristic feature of the traditionalist group according to the Jonsson (2000) taxonomy).

The second close comparison can be seen in the investor group, but in this case the similarities cannot be so clearly established. There is absolutely no doubt that this is the group that has invested most in the three different types of AMT, and as such it can be identifie with the group of large investors in the taxonomy of Boyer et al. (1996). Nevertheless, the relatively few plants included in our population, and the even smaller number that have what might be termed a generalized use of AMT, taken together with the differences in the scales utilized, means that the possibility cannot be discounted that our group of investor companies might actually correspond more to the group designated as generalist companies by the above-mentioned authors. Furthermore, although the AMTF mean for our investors group is very high (6.18), typical deviation is also rather high (3.87), as a result of which relative dispersion measured by the variation coefficien (standard deviation/mean) is $62.6 \%$. Although this value is not excessively high, it is nonetheless indicative of the fact that clear differences do exist from one plant to another in this cluster with respect to investments in AMTF. In other words, although we have detected this pattern in the Andalusian aeronautical sector, the differentiation by degrees found in Boyer et al. (1996) is not possible. At the same time, our investors group is equally identifiabl with the similarly named group in the Jonsson (2000) taxonomy. If we again apply the previously-stated argument regarding the relationship between level of investments and integration, which will be tested later, in this group, where investments reach the highest level for all three types of AMT, the degree of integration should also be high, this being a characteristic feature of the group of high investors of the Jonsson (2000) taxonomy.

Lastly, a clear similarity can be appreciated between our designer group and the similarly-named group in the Boyer et al. (1996) taxonomy, since their investments made in design AMTs are relatively high, while those made in manufacture and planning AMTs are not so high; in both cases, these latter types of investment are similar to those made by the traditionalist companies. Disregarding the integration variable, there do not seem to be any possible grounds for the identifi cation of our designer group with the hard integrators 
in Jonsson's taxonomy. The companies that Jonsson (2000) identifie as hard integrators are not only characterized by this main feature of integration, but also by the fact that they made their largest AMT investments in planning. This characterization cannot be applied in any sense to the designer companies that have been identifie in the Andalusian aeronautical sector.

The unquestionable identificatio of a group of designer companies in principle supports the hypothesis put forward by Boyer (1999) to the effect that the designer and the generalist companies follow different development patterns. A longitudinal study would be necessary to allow an assessment to be made of the way the companies in the sector evolve over a period of time.

\subsection{Explanatory factors for AMT investment patterns in the sector}

\subsubsection{Activity and patterns of investment}

The Fisher exact statistic was calculated with the aim of either accepting or rejecting possible dependency relationships between each pair of activities and clusters, obtaining the results shown in Table 11. As can be seen, although the null hypothesis of independence could be accepted for the majority of pairs,

Table 11

Correlation between activity and groups

\begin{tabular}{|c|c|c|c|}
\hline Activity & Traditionalists & Designers & Investors \\
\hline \multicolumn{4}{|c|}{ Sheet metal work $(n=3)$} \\
\hline FES & 0.566 & 0.242 & 0.404 \\
\hline $\mathrm{CC}$ & 0.180 & 0.324 & 0.211 \\
\hline \multicolumn{4}{|c|}{ Machining $(n=7)$} \\
\hline FES & 0.005 & 0.004 & 1.000 \\
\hline $\mathrm{CC}$ & 0.553 & 0.565 & 0.015 \\
\hline \multicolumn{4}{|c|}{ Engineering $(n=13)$} \\
\hline FES & 0.160 & 0.642 & 0.521 \\
\hline $\mathrm{CC}$ & 0.363 & 0.169 & 0.295 \\
\hline \multicolumn{4}{|c|}{ Design $(n=9)$} \\
\hline FES & 0.010 & 0.065 & 0.566 \\
\hline $\mathrm{CC}$ & 0.525 & 0.442 & 0.180 \\
\hline \multicolumn{4}{|c|}{ Assembly $(n=12)$} \\
\hline FES & 0.670 & 0.167 & 0.242 \\
\hline $\mathrm{CC}$ & 0.122 & 0.351 & 0.324 \\
\hline
\end{tabular}

FES: Fisher's exact statistic (bilateral exact significance) CC: contingency coefficient there are some clearly identifie dependency relationships in which the exact bilateral significance shown in bold, is less than 0.05 .

The firs dependency relationships of note are those between machining as a main activity and the traditionalist and designer groups, although in opposite ways. A relationship does exist between a company that does machining activity and its belonging to the designer group but, at the same time, there is a different relationship that shows that a company belonging to the traditionalist group does not usually do machining. It is perhaps surprising that machining work should be one of the characteristics of designer plants; but such a relationship appears logical if one considers that these companies either have to design their own parts or tooling, or else have to use design AMTs in order to be able to read the designs of their customers. Lastly, it should be noted that when a plant belongs to the traditionalist group, this is significantl related to its not undertaking design activities.

Putting aside statistically significan relationships, we believe that it is interesting to observe what the primary activities of the companies in each group are. This data is provided in Table 12 .

If we take into account the results obtained from Hypothesis 1 - as previously tested - and the data shown in Table 11, we have to accept that a relationship does exist between the industrial activity of a plant and its AMT investment pattern. Firstly, it can be clearly concluded that, in the population analyzed, most designer companies undertake machining work (although they may also undertake assembly work).

Table 12

Main activity by group

\begin{tabular}{ll}
\hline Group & Plants by activity \\
\hline Traditionalists $(n=9)$ & 3 Assembly \\
& 2 Assembly and sheet metal work \\
& 1 Assembly and composite materials \\
& 1 Engineering \\
& 1 Thermal treatment \\
& 1 Pipework and fina processes \\
& 3 Machining \\
Designers $(n=8)$ & 3 Machining and assembly \\
& 2 Engineering and design \\
Investors $(n=3)$ & 1 Assembly \\
& 1 Assembly and machining \\
& 1 Assembly and sheet metal work \\
\hline
\end{tabular}


Table 13

Size by group: results of ANOVA and LSD test

\begin{tabular}{lllll}
\hline & $\begin{array}{l}\text { Traditionalists } \\
\text { (cluster } 1, n=9)\end{array}$ & $\begin{array}{l}\text { Designers } \\
\text { (cluster 2, } n=8)\end{array}$ & $\begin{array}{l}\text { Investors } \\
\text { (cluster 3, } n=3 \text { ) }\end{array}$ & ANOVA \\
\hline Annual sales & {$[3]$} & {$[3]$} & {$[1,2]$} & \\
Mean & 641.666 & 660.500 & 15190.333 & $F=29.951$ \\
S.D. & 749.374 & 492.767 & 8567.303 & $P<\mathbf{0 . 0 0 1}$ \\
\hline
\end{tabular}

Numbers in brackets indicate other groups significantl different from the cluster in the multiple comparison LSD test $(P<0.05)$.

Secondly, although most of the plants in the traditionalist group can be seen to conduct a wide variety of activities, they are mainly engaged in assembly and not machining. Finally, in the investor group, where the plants are primarily concerned with assembly - an activity that can be automated, although this is not especially easy - the fundamental influenc of the size of the company is discernible. Section 5.2.2 deals with the relationship between the size of a plant and the cluster into which it falls.

\subsubsection{Size and patterns of investment}

To test the second hypothesis, a one-way ANOVA was performed together with the corresponding multiple comparison LSD test that allows the differences detected to be observed by pairs of clusters. The results are given in Table 13, where it can be appreciated how, as anticipated, differences do exist between the size of the plants in accordance with the cluster to which they belong.

The size of the companies in the investor group is significantl different from that of the companies in the other two groups, with the level of significanc being 0.01 in both cases. Consequently, it has to be accepted that there is a relationship between the size of a plant and its pattern of investment in AMT. However, no significan differences in size are seen between designer and traditionalist plants. Furthermore, in light of the means obtained for each, and of the level of significanc in the LSD test (0.990), it can be assumed that there is practically no difference in size between these last two groups. This is understandable if it is taken into account that, firstl , the cost of design AMTs is relatively low and their usefulness is relatively high as a piece of stand-alone equipment: they do not need to be closely integrated with other systems to be productive. This argument has been used in other empirical studies (Twigg et al., 1992; McDermott and Marucheck, 1995). Secondly, we have seen that in the traditionalist and designer groups the investments are very closely linked to the type of activity undertaken, a factor that has been confirme independently of company size.

What has been discussed so far suggests the existence of a certain size threshold above which investments in AMT are considerably higher, independently of the activity undertaken. Below this size threshold, investments basically seem to be related to type of activity, and differences between the similarly-sized traditionalist and designer companies can only be found in design AMT and, to a lesser extent, in manufacturing AMT (although in this latter case, not to a significant level). In the following sections, a closer look will be taken at the question of whether there are different patterns of investment, and at the way they are interpreted, apart from the differences that exist between large and small plants, and between plants that do machining work and those that do not.

\subsubsection{Competitive priorities and patterns of investment}

With regard to the third hypothesis, as has already been argued, the competitive priorities of the different groups in the taxonomy obtained should also be expected to vary, suggesting that the way a company's strategy is directed also influence the type of investments it makes. When an ANOVA was performed, this showed that the only significan difference between groups is with respect to the priority given to fl xibility, there being no differences in the rest of the priorities analyzed. The results detailing these differences are given in Table 14, together with the results of the LSD test (shown in brackets). These differences are only significan between the cluster of designers, on the one hand, and the clusters of traditionalists and investors, on the other, with the firs group being the one that attaches the greatest importance to fl xibility. It should firs be highlighted that the strategic orientation 
Table 14

Competitive priorities by group: results of ANOVA and LSD test

\begin{tabular}{|c|c|c|c|c|}
\hline & $\begin{array}{l}\text { Traditionalists } \\
\text { (cluster } 1, n=9 \text { ) }\end{array}$ & $\begin{array}{l}\text { Designers } \\
\text { (cluster } 2, n=8 \text { ) }\end{array}$ & $\begin{array}{l}\text { Investors } \\
\text { (cluster } 3, n=3 \text { ) }\end{array}$ & ANOVA \\
\hline \multicolumn{5}{|l|}{ Cost } \\
\hline Mean & 4.48 & 4.58 & 6.00 & $F=2.629$ \\
\hline S.D. & 0.85 & 1.32 & 0.00 & $P=0.101$ \\
\hline \multicolumn{5}{|l|}{ Quality } \\
\hline Mean & 6.33 & 6.54 & 6.22 & $F=0.430$ \\
\hline S.D. & 0.62 & 0.59 & 0.39 & $P=0.658$ \\
\hline \multicolumn{5}{|l|}{ Delivery } \\
\hline Mean & 6.33 & 6.50 & 7.00 & $F=1.063$ \\
\hline S.D. & 0.87 & 0.53 & 0.00 & $P=0.367$ \\
\hline Flexibility & {$[2]$} & {$[1,3]$} & {$[2]$} & \\
\hline Mean & 4.18 & 5.35 & 3.80 & $F=3.624$ \\
\hline S.D. & 1.38 & 0.68 & 0.35 & $P<0.05$ \\
\hline
\end{tabular}

Numbers in brackets indicate other groups significantl different from the cluster in the multiple comparison LSD test $(P<0.05)$.

of plants in this sector is primarily linked to the objectives of delivery and quality, with costs and fl xibility being given relatively little importance. The larger plants are without doubt those that afford the least relative importance to the objective of fl xibility (3.80) compared with a mean of 4.18 for the traditionalists and 5.35 for the designers. This might be a reflectio of the need of smaller companies to respond to demands made by their larger customers (some of which are included in the investor group). Larger plants in this sector do not seem to be subject to this type of pressure. Nevertheless, as has been previously indicated, the differences that were found between the groups were not between the larger factories - the investors - and the smaller ones - the traditionalists and the designers, as the differences between traditionalists and investors are not statistically significant However, if the two groups with no difference in size - traditionalists and designers - are compared, we fin that the designers, who are more inclined towards investment in AMT, are also apparently more committed to fl xibility. Given that the results obtained do not allow clear conclusions to be drawn regarding any effects strategic priorities might have on AMT investment, this relationship is significan inasmuch as it might suggest that those smaller firm that have invested in AMT to a greater degree, i.e. the designers, have benefite from the investments by achieving greater $\mathrm{fl}$ xibility in their procedures which they can then use to their competitive advantage. This relationship requires further analysis, however.

\subsubsection{Information elements and patterns of investment}

Table 15 has been drawn up to analyze this aspect and shows that the factors that carried least relative weight for providing information on AMT were the plant's own workers and, to an even lesser degree, information programs run by government departments. This fact is quite striking, as the aeronautical sector is considered to be a strategic industry by the Andalusian authorities. Despite this, the companies feel that the information they obtain from the various government departments is not very important for gaining knowledge about the advanced manufacturing technologies that could be applied to their procedures. This might be a reflectio of some oversight on the part of the Authorities, mostly regional government departments, especially when it is realized that, in some cases, the sector is not very aware of these technologies.

For the traditionalists and the investors, the most important factor is information obtained from other companies, followed by information received from suppliers. The designers, however, mostly obtain information about AMT at trades fairs and also through their suppliers. This might reflec greater diligence on the part of their company executives given that, as the companies are small in size, they are more inclined 
Table 15

Information elements by group: results of ANOVA

\begin{tabular}{|c|c|c|c|c|}
\hline & $\begin{array}{l}\text { Traditionalists } \\
\text { (cluster } 1, n=9 \text { ) }\end{array}$ & $\begin{array}{l}\text { Designers } \\
\text { (cluster 2,n=8) }\end{array}$ & $\begin{array}{l}\text { Investors } \\
\text { (cluster } 3, n=3 \text { ) }\end{array}$ & ANOVA \\
\hline \multicolumn{5}{|c|}{ Information from suppliers } \\
\hline Mean & 3.12 & 3.56 & 2.33 & $F=0.381$ \\
\hline S.D. & 2.35 & 2.02 & 1.15 & $P=0.689$ \\
\hline$N$ & 8 & 8 & 3 & \\
\hline \multicolumn{5}{|c|}{ Information from workers } \\
\hline Mean & 2.20 & 1.87 & 1.00 & $F=0.749$ \\
\hline S.D. & 1.73 & 1.35 & 0.00 & $P=0.489$ \\
\hline$N$ & 8 & 8 & 3 & \\
\hline \multicolumn{5}{|c|}{ Other companies } \\
\hline Mean & 4.41 & 2.97 & 5.66 & $F=2.194$ \\
\hline S.D. & 2.38 & 1.83 & 1.15 & $P=0.144$ \\
\hline$N$ & 8 & 8 & 3 & \\
\hline \multicolumn{5}{|c|}{ Trades fairs } \\
\hline Mean & 3.00 & 3.83 & 1.00 & $F=1.793$ \\
\hline S.D. & 2.20 & 2.51 & 0.00 & $P=0.198$ \\
\hline$N$ & 8 & 8 & 3 & \\
\hline \multicolumn{5}{|c|}{ Journals and magazines } \\
\hline Mean & 2.62 & 3.31 & 1.00 & $F=1.786$ \\
\hline S.D. & 2.06 & 1.79 & 0.00 & $P=0.200$ \\
\hline$N$ & 8 & 8 & 3 & \\
\hline \multicolumn{5}{|c|}{ Government departments and agencies } \\
\hline Mean & 1.50 & 1.16 & 1.00 & $F=0.390$ \\
\hline S.D. & 1.41 & 0.35 & 0.00 & $P=0.684$ \\
\hline$N$ & 8 & 8 & 3 & \\
\hline
\end{tabular}

to invest in AMT than traditionalists. Nevertheless, the result of greatest note is that, contrary to what is put forward in Hypothesis 4, no difference can be seen between the groups with respect to the relative importance afforded to different information sources, whereby it should be concluded that the information sources used when investing in AMT have no special effect on the level of investment made by the plants in the population.

\subsubsection{Catalyst elements and patterns of investment}

With regard to catalyst elements, however, it can be seen in Table 16 that the answers basically point to one or two factors, with the others being afforded little or no importance whatsoever. The most important catalyst factor that drives companies to invest is expansion. In fact, the only differences between the various groups shown by ANOVA were with respect to this factor, which partially confirm Hypothesis 5. The LSD analysis indicates that there are differences between the investor, and the traditionalist and designer groups in this respect, with expansion being an especially relevant issue for investment in AMT for the last two. This causes us to again highlight that a fundamental factor in this sector for investing in AMT is the company being of a certain minimum size. As investor plants have already reached this minimum size, it is not a requirement for them to be going through a process of expansion in order to make new investments. For the other two groups, however, the expansion process and the subsequent increase in size of the company is fundamental if they are to have access to said technologies. It can also be said that, on many occasions, especially depending on the type of activity in question, a plant will fin it difficul to win new orders and to expand if it does not possess the capabilities that this technology affords. It should also be pointed out that many of the plants, even the larger ones, made some reference to the need to invest in order not to be excluded from the market. 
Table 16

Catalyst elements by group: results of ANOVA and LSD test

\begin{tabular}{|c|c|c|c|c|}
\hline & $\begin{array}{l}\text { Traditionalists } \\
\text { (cluster } 1, n=9 \text { ) }\end{array}$ & $\begin{array}{l}\text { Designers } \\
\text { (cluster } 2, n=8)\end{array}$ & $\begin{array}{l}\text { Investors } \\
(\text { cluster } 3, n=3)\end{array}$ & ANOVA \\
\hline \multicolumn{5}{|c|}{ Arrival of new employee/executive } \\
\hline Mean & 1.00 & 1.54 & 1.00 & $F=1.290$ \\
\hline S.D. & 0.00 & 1.09 & 0.00 & $P=0.303$ \\
\hline$N$ & 8 & 8 & 3 & \\
\hline Plans for expansion & {$[3]$} & {$[3]$} & {$[1,2]$} & \\
\hline Mean & 5.25 & 4.64 & 1.00 & $F=4.838$ \\
\hline S.D. & 1.98 & 2.39 & 0.00 & $P<0.05$ \\
\hline$N$ & 8 & 8 & 3 & \\
\hline \multicolumn{5}{|l|}{ Rising profit } \\
\hline Mean & 2.83 & 3.22 & 1.00 & $F=1.583$ \\
\hline S.D. & 2.05 & 1.93 & 0.00 & $P=0.236$ \\
\hline$N$ & 8 & 8 & 3 & \\
\hline \multicolumn{5}{|c|}{ Injection of outside capital } \\
\hline Mean & 1.00 & 1.06 & 1.00 & $F=0.662$ \\
\hline S.D. & 0.00 & 0.17 & 0.00 & $P=0.530$ \\
\hline$N$ & 8 & 8 & 3 & \\
\hline \multicolumn{5}{|c|}{ Existence of skilled labor } \\
\hline Mean & 1.75 & 1.37 & 1.00 & $F=0.510$ \\
\hline S.D. & 1.38 & 1.06 & 0.00 & $P=0.610$ \\
\hline$N$ & 8 & 8 & 3 & \\
\hline
\end{tabular}

Numbers in brackets indicate other groups significantl different from the cluster in the multiple comparison LSD test $(P<0.05)$.

\subsection{Effects of investment patterns identifie in the} sector

\subsubsection{Investment patterns and integration}

A one-way ANOVA was performed to test the fourth hypothesis, the results of which can be seen in Table 17. The results of the multiple comparison LSD test are included in the table in brackets.

It can be seen that the degree of integration differs significantl from one cluster to another. In other words, as expected, there is a significan difference between the degree of integration found in the investor group of companies and those of the other two clusters; in addition, the difference in level of inte- gration between the designer and traditionalist companies is equally significant Therefore, the null hypothesis has to be rejected and it must be accepted that there are differences in the degree of integration from one investment pattern identifie in the sector to another.

These results confir the finding of Boyer et al. (1996). Nevertheless, whereas in the cited study differences in integration between the traditionalist and designer companies were not found, in our population this difference can be clearly appreciated. This could be due to the fact that, in our study, in addition to the significan difference in the AMTD variable, the difference between the means for investment in

Table 17

Integration by group: results of ANOVA and LSD test

\begin{tabular}{lllll}
\hline & $\begin{array}{l}\text { Traditionalists } \\
(\text { cluster } 1, n=9)\end{array}$ & $\begin{array}{l}\text { Designers } \\
\text { (cluster 2, } n=8)\end{array}$ & $\begin{array}{l}\text { Investors } \\
\text { (cluster 3, } n=3)\end{array}$ & ANOVAs \\
\hline Integration & {$[2,3]$} & {$[1,3]$} & {$[1,2]$} & $F=18.290$ \\
Mean & 1.31 & 3.33 & 6.17 & $P<0.001$ \\
S.D. & 0.46 & 1.84 & 0.58 & $P$ \\
\hline
\end{tabular}

Numbers in brackets indicate other groups significantl different from the cluster in the multiple comparison LSD test $(P<0.05)$. 
Table 18

Performance by group: results of ANOVA

\begin{tabular}{lllll}
\hline & $\begin{array}{l}\text { Traditionalists } \\
\text { (cluster 1, } n=9)\end{array}$ & $\begin{array}{l}\text { Designers } \\
\text { (cluster 2, } n=8)\end{array}$ & $\begin{array}{l}\text { Investors } \\
\text { (cluster 3, } n=3 \text { ) }\end{array}$ & ANOVA \\
\hline Growth & & & & $F=3.086$ \\
Mean & 4.94 & 6.00 & 4.50 & $P=0.072$ \\
S.D. & 0.84 & 1.39 & 0.00 & $F=1.382$ \\
Profi & & & & $P=0.280$ \\
Mean & 4.44 & 5.28 & 5.00 & 0.00 \\
S.D. & 1.04 & 1.15 & & $P$ \\
\hline
\end{tabular}

manufacturing AMT is rather more marked $(0.81$ for the traditionalist group and 2.15 for the designer group) than in Boyer et al. (1996) (in which means of 2.43 and 2.62, respectively, are reported). Although this is not sufficien to be considered statistically significant it could allow the difference in degree of integration between the designer and the traditionalist groups to be considered significant

\subsubsection{Investment patterns and performance}

On analyzing the relationship between investment patterns and company performance, the finding show that the differences between groups are not significant in either of the two aspects used to measure performance; however, they are closer to being significan in the case of growth than in profitabilit (see Table 18).

The results obtained tend to corroborate the find ings of Boyer et al. (1996), inasmuch as differences in investment performance were not found between clusters. The authors put forward various possible causes to explain this result: the quality of the implementation process, eventualities related to customers and company products, a delay between the investments being made and the resulting improvement in performance being felt, or the principle of equifinalit . Any of these could, a priori, apply in our study, although with conditions. Thus, for example, although it is true that many of the investments analyzed were made very recently, others had been made several years earlier, and so the influenc of any possible delay could not be generalized; a longitudinal study would be required comparing the results obtained by particular companies over the course of time. Furthermore, the characteristics of the population studied lead us to accept that the relationships between the companies and their customers/suppliers are very similar in all cases; for this reason, the influenc this possible cause has may not carry much weight in explaining the differences or absence of differences in performance. Regarding the quality of the implementation process, the results obtained in other areas of the broader research project suggest that the only factor significantl related to better investment performance is the training of the personnel involved, although this relationship is not observed when considering overall company performance. Finally, several authors have emphasized the importance the principle of equifinalit has for typologies and taxonomies with respect to corporate strategy. Many studies have come to the conclusion that technology per se does not correlate with an improvement in performance (Krafcik, 1988; Matthews and Foo, 1991; Boyer et al., 1997; Swamidass and Kotha, 1998; Cagliano and Spina, 2000; Kotha and Swamidass, 2000). The results obtained in our study support the principle of equifinalit, i.e. that various different paths or strategies followed by a company could lead to identical results.

\subsubsection{Investment patterns and difficultie in the adoption and implementation process}

With regard to the eighth hypothesis, it was expected that the degree of complexity of the equipment installed, and the amount of previous experience companies had with large-scale investments would in some way be reflecte in the factors that the different plants considered to have most hampered the adoption and implementation process. The ANOVA results shown in Table 19 demonstrate, however, that there is no significan relationship between groups and specifi difficulties This means that Hypothesis 8 should be rejected. 
Table 19

Difficultie by group: results of ANOVA

\begin{tabular}{|c|c|c|c|c|}
\hline & $\begin{array}{l}\text { Traditionalists } \\
\text { (cluster } 1, n=9 \text { ) }\end{array}$ & $\begin{array}{l}\text { Designers } \\
\text { (cluster } 2, n=8 \text { ) }\end{array}$ & $\begin{array}{l}\text { Investors } \\
\text { (cluster } 3, n=3 \text { ) }\end{array}$ & ANOVA \\
\hline \multicolumn{5}{|c|}{ Lack of skilled labor } \\
\hline Mean & 3.28 & 5.47 & 2.76 & $F=2.831$ \\
\hline S.D. & 2.26 & 2.17 & 1.32 & $P=0.089$ \\
\hline$N$ & 8 & 8 & 3 & \\
\hline \multicolumn{5}{|c|}{ Loss of fl xibility } \\
\hline Mean & 1.00 & 1.25 & 1.56 & $F=1.095$ \\
\hline S.D. & 0.00 & 0.71 & 0.98 & $P=0.358$ \\
\hline$N$ & 8 & 8 & 3 & \\
\hline \multicolumn{5}{|c|}{ Equipment breaking down } \\
\hline Mean & 2.07 & 2.53 & 2.20 & $F=0.159$ \\
\hline S.D. & 1.23 & 2.19 & 0.17 & $P=0.854$ \\
\hline$N$ & 8 & 8 & 3 & \\
\hline \multicolumn{5}{|c|}{ Reorganization of departments } \\
\hline Mean & 2.71 & 2.62 & 2.76 & $F=0.011$ \\
\hline S.D. & 1.64 & 1.59 & 1.32 & $P=0.989$ \\
\hline$N$ & 8 & 8 & 3 & \\
\hline \multicolumn{5}{|c|}{ Reticence amongst employees } \\
\hline Mean & 2.08 & 2.27 & 1.00 & $F=1.224$ \\
\hline S.D. & 1.05 & 1.51 & 0.00 & $P=0.320$ \\
\hline$N$ & 8 & 8 & 3 & \\
\hline \multicolumn{5}{|c|}{ Reticence amongst executives } \\
\hline Mean & 1.46 & 1.00 & 1.00 & $F=2.097$ \\
\hline S.D. & 0.73 & 0.00 & 0.00 & $P=0.155$ \\
\hline$N$ & 8 & 8 & 3 & \\
\hline \multicolumn{5}{|c|}{ Difficultie with evaluation } \\
\hline Mean & 1.91 & 2.28 & 2.46 & $F=0.149$ \\
\hline S.D. & 1.00 & 2.42 & 0.40 & $P=0.863$ \\
\hline$N$ & 8 & 8 & 3 & \\
\hline \multicolumn{5}{|c|}{ Difficultie with performance measurement } \\
\hline Mean & 1.71 & 1.83 & 3.13 & $F=1.423$ \\
\hline S.D. & 0.95 & 1.56 & 0.98 & $P=0.272$ \\
\hline$N$ & 7 & 8 & 3 & \\
\hline \multicolumn{5}{|c|}{ Difficultie with financin } \\
\hline Mean & 3.37 & 1.96 & 1.00 & $F=1.582$ \\
\hline S.D. & 2.56 & 2.07 & 0.00 & $P=0.236$ \\
\hline$N$ & 8 & 8 & 3 & \\
\hline
\end{tabular}

We do believe that there is a series of circumstances of note, however. It should firstl be noted that none of the means that the factors achieved in any of the three groups are overly high, and on hardly any occasion is the middle value of the scale reached. It can be deduced from this that investor plants have not come up against any insurmountable problems. Nevertheless, the difficultie caused by a lack of skilled labor should be highlighted, especially for the factories in the designer group. With quite a low $P$ level $(P=0.089)$, however, these differences are not significan in statistical terms. Even so it can be ascertained that it is the smallest factories with the highest levels of investment in design and manufacturing AMT, in other words, the designers, who most suffer from the lack of skilled labor (5.47 points on a scale of 7). As the equipment found in these factories is as complex as that in the traditionalist companies, this difficult 
may arise out of the need for said equipment to be integrated; it should not be forgotten that the level of activity integration in designer plants is significantl higher than in traditionalist factories. The fundamental differences that set the traditionalist companies apart from the other two groups are in the funding of investments, which could at one and the same time explain why they are the companies with the smallest investments. The fact that this cannot be seen to be true in the case of the designers eliminates the possibility that it is simply a collateral effect of size. Finally, the investor plants consider the main difficult in the adoption and implementation process to be in the gauging of the performance of the investment. We believe that this circumstance cannot be explained by smaller companies having an ability to evaluate and gauge the performance of investments more easily, but that larger companies are more aware of the diffi culty that carrying out both processes correctly entails when intangible factors are taken into account.

\section{Conclusions and future lines of research}

The empirical analysis that was conducted has enabled us to establish a taxonomy of three groups of companies that differ from each other in accordance with their investments in the three different types of AMT, which hints at different technological strategies. Plants in the sector under study have been identifie as traditionalists, designers and investors and are also differentiated in size, degree of integration and type of activity. In general, the traditionalists are smaller companies with relatively limited investments in AMT and a low degree of integration, which do not undertake machining work; the designers are also smaller companies but with relatively high investments in design AMT and an intermediate degree of integration, which do undertake machining; the investors are larger plants with the highest levels of investment in all three types of AMT and with a high degree of integration.

On the basis of the results, no clear conclusions can be drawn regarding any influenc competitive priorities might have on investments, as no clear relationship is discernible. Although this is not the firs time that no relationship has been observed between strategy and investments, it is, nevertheless, important if we bear in mind that in previous studies evidence has been found that indicates that a failure to align investment and strategy could be one of the reasons for heavier investment in AMT not being reflecte in greater performance (Kotha and Swamidass, 2000). The only clearly significan difference that can be seen is between the designers and the other two groups, and this with respect to the degree of priority given to fl xibility as an objective. However, it remains to be determined whether or not this relationship really implies a reorientation of strategy after the acquisition of AMT with the consequent reorientation of the capabilities that these new technologies provide. The opinion that the relationship between corporate strategy and investment in technology is inherently dynamic in both directions has been expressed by several authors in recent years (Schroeder et al., 1995; Clark, 1996; Banerjee, 2000). It is logical to consider that the exploitation of newly-acquired AMT will generate new capabilities that would require pertinent changes to be made to the company's previous competitive strategy. In this context, companies lacking AMT would have fewer strategic options and a narrower scope of action; if companies that do acquire AMT do not have a well-define strategic framework for their business, the options opened up by AMT may go unrecognized. This could lead them to opt for an inefficien course of action, failing to develop the new capabilities available to the greatest extent and failing to take advantage of potential competitive advantages. Despite these considerations, empirical evidence for this relationship is still scant. This is due to the fact that, on the one hand, the idea has only very recently been put forward that the technology employed, as an internal component of an organization, might act to inspire its strategy (Parthasarthy and Sethi, 1992), and, on the other, many companies, particularly the smaller ones, do not deliberately develop any kind of strategic planning, thus making observation of changes in strategy difficult

Furthermore, differences in plant performance found between the groups are, in general terms, minimal, as in other studies (Boyer et al., 1996; Swamidass and Kotha, 1998; Cagliano and Spina, 2000). This would support the principle of equifinality - th view that for any company, different paths or strategies exist that could lead to identical results. However, it could also be indicative of what has been previously suggested: that a lack of alignment of plant strategy and the type of AMT investment made might lead to 
the improvement expected from the investment not being fully achieved.

The identificatio of an investors group that is comprised of the three largest plants in the population bears witness to the importance of the size variable for explaining investments in the sector, as has been the case with all previous studies on AMT investment taxonomies, where this relationship is likewise present. The groups that make the heaviest investments are the ones comprised of the biggest companies. Nevertheless, the fact that the smaller plants and companies in the population that was analyzed are spread between different groups suggests that size cannot be the only variable that affects the grouping process. The fact is that when it comes to investing in the sector under analysis, the crucial variables are the size of a plant and the activity it conducts. However, the reason why differences cannot be seen in other studies with respect to activity might be that a large enough variety of activities had not been taken into consideration. Despite the fact that plants in different sectors were considered, they all conducted identical activities. Our analysis has been of a single sector, but we go into the specifi activities conducted in detail.

Nonetheless, on their own these two factors per se cannot explain all the differences found between the groups. Once a clear difference in competitive priorities has been ruled out, there is one factor that has shown itself to be significant whether the company is in the process of expansion or not. However, this undoubtedly takes us back indirectly to the question of size.

It is true that the population analyzed in this sectoral and regional research study comprises plants conducting their activities exclusively or mainly in the aeronautical sector and in a very specifi geographical region. The findings should be highly explanatory for the population as long as we accept that the data that was collected is accurate as a result of the steps that were taken to prevent certain factors affecting it, such as the degree to which it could be easily understood, and the level of attention or mood of the interviewee. It would not in principle be correct to consider extrapolating the results to any other sample or population and it was never intended for the statistical analysis to be inferred in a general way. On the contrary, it could be said that this contribution relies, rather on the possibility of a logical extrapolation to circumstances where the finding might apply, and researchers can judge whether the particular finding would be valid. However, from the characteristics presented by the groups, it can be stated that the patterns of behavior shown with respect to investments in AMT in the sector are similar to those detected in other sectors and geographical areas; hence, one can have confidenc in the consistency of certain patterns beyond geographical and sectoral bounds. With respect to this question, an in-depth study to confir the existence of a technology strategy that is heavily geared towards design AMTs would seem to be necessary. Such a strategy has previously been identifie (Boyer et al., 1996) and clearly re-emerges in this study, although it was not evident in the study carried out by Jonsson (2000). Boyer's (1999) more recent findings which suggested that designer and generalist companies follow different development patterns, support the existence of this strategy.

In our case, a longitudinal analysis would help shed more light on the evolution of investment patterns in the sector and on other aspects, too, such as whether the benefit of AMT for company performance can be perceived more clearly in the longer term or whether the plants that did not invest in AMT have disappeared or been absorbed; three traditionalist plants had already been bought out by larger Spanish or overseas companies by the end of 2002 . There have been considerable changes in the sector since the start of this research. During 2000 and for most of 2001, the excellent prospects for the sector in Andalusia-riding on the back of the buoyant situation of the sector in Europe, with satisfactory growth anticipated, and in the midst of restructuring as a result of the creation of EADS - produced a number of changes in its make-up. Several other companies have opened plants in the region and it was hoped that more would follow, given the advantages offered (including, for example, low manufacturing costs, the availability of skilled labor, the tradition of aeronautical activity in the region, good links with the north of Europe, subsidies from the EU, being classifie as a zone 1 , and the fact that the CASA fina assembly plant is located in Seville). In addition, many companies had considerably increased their workforce and sales in the expectation that there would be a prolonged increase in workload. However, the circumstances surrounding the sector have altered dramatically since the terrorist attacks of 11 September 2001 in the USA; for this reason, the results of 
such a longitudinal analysis could similarly be considerably affected.

On the other hand, it has not been possible to establish any statistically-significan relationship between the other factors that were considered in the study and the groups that were identifie in the population being analyzed. Given the previously-mentioned limitations to the population, however, we are of the opinion that some of these issues are worthy of a more in-depth analysis with more general populations and samples.

Finally, there is one other aspect that has arisen out of our research which, although not directly related to the goals of the study, is, in our opinion, of special interest. As has been explained in the methodology, the scales of measurement utilized have been validated in previous studies as being highly reliable, and this has also been corroborated in our study in most cases. Nevertheless, it has also been confirme that the scales of measurement for strategic operations objectives, again clearly validated in other research, have not been found suitable for our purposes in this study. It is therefore considered that an in-depth analysis to make these scales appropriate for different sectors and their priorities is a topic that merits further investigation.

\section{Acknowledgements}

We would like to express our gratitude to all those people and companies who co-operated in the field work, without whose collaboration and interest, our project would not have been possible. We also wish to thank Professor José Luis Pérez Díez de los Ríos for his invaluable assistance with the statistical analysis. In addition, the authors acknowledge the support and insightful comments of an associate editor and three anonymous reviewers, whose concerns and suggestions have resulted in a significantl improved paper. This research has been partially funded by the CICYT (Spanish Inter-Ministerial Commission for Science and Technology) through project number PB1869, and by the Andalusian Regional Government.

\section{References}

Adler, P.S., 1988. Managing fl xible automation. California Management Review 30 (3), 34-56.
Aggarwal, S., 1995. Emerging hard and soft technologies: current status, issues and implementation problems. Omega International Journal of Management Science 23 (3), 323-339.

Álvarez Gil, M.J., 1993. Los Sistemas de Información y las Nuevas Tecnologías Productivas. In: Carmona Moreno, S. (Ed.), Cambio Tecnológico y Contabilidad de Gestión. Instituto de Contabilidad y Auditoría de Cuentas, Ministerio de Economía y Hacienda, Madrid, pp. 243-269.

Aquilano, N.J., Chase, R.B., 1991. Fundamentals of Operations Management. Irwin, Homewood, IL.

Avella Camarero, L., Fernández Sánchez, E., 2000. Does manufacturing determine a firm' competitiveness? Evidence in a sample of Spanish industrial companies. In: Proceedings of the First World Conference on Production and Operations Management (CD-ROM), Seville.

Babbar, S., Rai, A., 1990. Computer integrated fl xible manufacturing: an implementation framework. International Journal of Operations and Production Management 10 (1), 4250.

Banerjee, S.K., 2000. Developing manufacturing management strategies: influenc of technology and other issues. International Journal of Production Economics 64 (1-3), 79-90.

Boer, H., Hill, M., Krabbendam, K., 1990. FMS implementation management: promise and performance. International Journal of Operations and Production Management 10 (1), 5-20.

Boyer, K.K., 1999. Evolutionary patterns of fl xible automation and performance. Management Science 45 (6), 824-842.

Boyer, K.K., McDermott, C., 1999. Strategic consensus in operations strategy. Journal of Operations Management 17 (3), 289-305.

Boyer, K.K., Pagell, M., 2000. Measurement issues in empirical research: improving measures of operations strategy and advanced manufacturing technology. Journal of Operations Management 18 (3), 361-374.

Boyer, K.K., Ward, P.T., Leong, G.K., 1996. Approaches to the factory of the future. An empirical taxonomy. Journal of Operations Management 14 (4), 297-313.

Boyer, K.K., Leong, G.K., Ward, P.T., Krajewski, L.J., 1997. Unlocking the potential of advanced manufacturing technologies. Journal of Operations Management 15 (4), 331-347.

Boyer, K.K., Bozarth, C., McDermott, C. (Eds.), 2000. Configura tions in operations management: taxonomies and typologies. Journal of Operations Management 18 (6) (Special issue).

Bozarth, C., McDermott, C., 1998. Configuration in manufacturing strategy: a review and directions for future research. Journal of Operations Management 16 (4), 427-439.

Cagliano, R., Spina, G., 2000. Advanced manufacturing technologies and strategically fl xible production. Journal of Operations Management 18 (2), 169-190.

Camisón Zornoza, C., 1994. Dirección de Operaciones y Cultura de la Producción Estratégica: El Caso de la Gran Empresa Industrial Española. Dirección y Organización 10, 33-42.

Chen, R., 1996. Technological expansion: the interaction between diversificatio strategy and organizational capability. Journal of Management Studies 33 (5), 649-666.

Clark, K.B., 1996. Competing through manufacturing and the new manufacturing paradigm: is manufacturing strategy passé? Production and Operations Management 5 (1), 42-58. 
Cohen, M.A., Apte, U.M., 1997. Manufacturing Automation. McGraw-Hill, New York.

Corbett, L.M., 1996. A comparative study of the operations strategies of globally- and domestically-oriented New Zealand manufacturing firms International Journal of Production Research 34 (10), 2677-2689.

Dean Jr., J.W., Yoon, S.J., Susman, G.I., 1992. Advanced manufacturing technology and organization structure: empowerment or subordination? Organization Science 3 (2), 203-229.

Díez de Castro, E.P., Galán González, J.L., Landa Bercebal, J., Leal Millán, A., 1995. La Empresa en Andalucía. Instituto de Fomento de Andalucía, Civitas, Sevilla.

Doty, D.H., Glick, W.H., 1994. Typologies as a unique form of theory building: toward improved understanding and modelling. The Academy of Management Review 19 (2), 230-251.

Dunne, T., 1994. Plant age and technology use in U.S. manufacturing industries. RAND Journal of Economics 25 (3), 488499.

Eurostat, 1999. Structural Business Statistics. Industry, (Construction, Trade and Services). Statistical Offic of the European Communities. Datashop Eurostat, Madrid.

Everitt, B., 1981. Cluster Analysis. Heinemann Educational Book, London.

Fine, C.H., 1990. New manufacturing technologies. In: Moody, P.E. (Ed.), Strategic Manufacturing. Dynamic New Directions for the 1990s. Business One Irwin, pp. 257-273.

Flynn, B.B., Sakakibara, S., Schroeder, R.G., Bates, K.A., Flynn, E.J., 1990. Empirical research methods in operations management. Journal of Operations Management 9 (2), 250284.

Gerwin, D., Kolodny, H., 1992. Management of Advanced Manufacturing Technology. Strategy, Organization \& Innovation. Wiley, New York.

Gordon, J., Sohal, A.S., 2001. Assessing manufacturing plant competitiveness. An empirical fiel study. International Journal of Operations and Production Management 21 (1-2), 233-253.

Gupta, A., Chen, I.J., Chiang, D., 1997. Determining organizational structure choices in advanced manufacturing technology management. Omega International Journal of Management Science 25 (5), 511-521.

Hair, J.F., Anderson, R.E., Tatham, R.L., Black, W.C., 1999. Análisis Multivariante, 5th ed. Prentice-Hall, Englewood Cliffs, NJ.

Harrison, N.J., 1995. Use of taxonomies to assess manufacturing strategies. International Journal of Technology Management, Special Publication on Emerging Technological Frontiers to Increasing Competitiveness, pp. 213-247.

Hensley, R.L., 1999. A review of operations management studies using scale development techniques. Journal of Operations Management 17 (3), 343-358.

Hoskisson, R.E., Hitt, M.E., Johnson, R.A., Moesel, D.D., 1993. Construct validity of an objective (entropy) categorical measure of diversificatio strategy. Strategic Management Journal 14 (3), 215-235.

Jonsson, P., 2000. An empirical taxonomy of advanced manufacturing technology. International Journal of Operations and Production Management 20 (12), 1446-1474.
Kaighobadi, M., Venkatesh, K., 1994. Flexible manufacturing systems: an overview. International Journal of Operations and Production Management 14 (4), 26-49.

Kelley, M.R., Brooks, H., 1991. External learning opportunities and the diffusion of process innovations to small firms Technological Forecasting and Social Change 39, 103-125.

Ketchen, D., Shook, C., 1996. The application of cluster analysis in strategic management research: an analysis and critique. Strategic Management Journal 17, 441-458.

Kotha, S., Swamidass, P.M., 2000. Strategy, advanced manufacturing technology and performance: empirical evidence from U.S. manufacturing firms Journal of Operations Management 18 (3), 257-277.

Krafcik, J.F., 1988. Triumph of the lean production systems. Sloan Management Review 30 (1), 41-52.

Krajewski, L.J., Ritzman, L.P., 1996. Operations Management: Strategy and Analysis. Addison-Wesley, Reading, MA.

Langley, A., Truax, J., 1994. A process study of new technology adoption in smaller manufacturing firms Journal of Management Studies 31 (5), 619-652.

Lefebvre, L.A., Langley, A., Harvey, J., Lefebvre, E., 1992. Exploring the strategy-technology connection in small manufacturing firms Production and Operations Management 1 (3), 269-285.

Lehmann, D.R., 1979. Market Research and Analysis. Irwin, Homewood, IL.

Lei, D., Goldhar, J.D., 1991. Computer-integrated manufacturing (CIM): redefinin the manufacturing fir into a global service business. International Journal of Operations and Production Management 11 (10), 5-18.

Liu, S., Chen, R., 1998. Understanding and implementing CIM through BPR. International Journal of Operations and Production Management 18 (11), 1125-1133.

Machuca, J.A.D., Álvarez Gil, M.J., García González, S., Domínguez Machuca, M.A., Ruiz Jiménez, A., 1995. Dirección de Operaciones: Aspectos Estratégicos en la producción y los servicios. McGraw-Hill, Madrid.

Malhotra, M.K., Grover, V., 1998. An assessment of survey research in POM: from constructs to theory. Journal of Operations Management 16 (4), 407-425.

Mansfield E., 1993. The diffusion of fl xible manufacturing systems in Japan. Management Sciences 39 (2), 149-159.

Martínez Sánchez, A., 1996. Adopting AMT: experience from Spain. Journal of Manufacturing Systems 15 (2), 133-140.

Matthews, J.P., Foo, S.T., 1991. Equipment dedication and automation: some empirical findings Omega International Journal of Management Science 19 (5), 475-484.

McDermott, C.M., Marucheck, A., 1995. Training in CAD: an exploratory study of methods and benefits IEEE Transactions on Engineering Management 42 (4), 410-418.

McDermott, C.M., Stock, G.N., 1999. Organizational culture and advanced manufacturing technology implementation. Journal of Operations Management 17 (5), 521-533.

Mechling, G.W., Pearce, J.W., Busbin, J.W., 1995. Exploiting AMT in small manufacturing firm for global competitiveness. International Journal of Operations and Production Management 15 (2), 61-76. 
Meredith, J.R., 1987. The strategic advantages of the factory of the future. California Management Review 29 (3), 27-41.

Miller, D., 1996. Configuration revisited. Strategic Management Journal 17, 505-512.

Miller, J.G., Roth, A.V., 1994. Taxonomy of manufacturing strategies. Management Science 40 (3), 285-304.

Milligan, G.W., Cooper, M.C., 1985. An examination of procedures for determining the number of clusters in a data set. Psychometrika 2, 159-179.

Milling, P.M., 1997. Computer integrated manufacturing in German industry: aspirations and achievements. International Journal of Operations and Production Management 17 (10), 1034-1045.

Nagalingam, S.V., Lin, G.C.I., 1999. Latest developments in CIM. Robotics and Computer Integrated Manufacturing Systems 15, 423-430.

Naik, B., Chakravarty, A.K., 1992. Strategic acquisition of new manufacturing technology: a review and research framework. International Journal of Production Research 30 (6), 1575-1601.

Nunnally, J.C., 1978. Psychometric Theory, 2nd ed. McGraw-Hill, New York.

O’Leary-Kelly, S.W., Vokurka, R.J., 1998. The empirical assessment of construct validity. Journal of Operations Management 16 (4), 387-405.

Parthasarthy, R., Sethi, S.P., 1992. The impact of fl xible automation on business strategy and organizational structure. Academy of Management Review 17, 86-111.

Porter, M.E., 1987. Ventaja Competitiva: Creación y Sostenimiento de un Desempeño Superior, CECSA.

Romeo, A.A., 1975. Interindustry and interfir differences in the rate of diffusion of an innovation. Review of Economics and Statistics 57, 311-319.

Rosenthal, L., 1984. 'Progress Toward the Factory of the Future'. Journal of Operations Management 4 (3), 203-229.

Roth, A.V., 1996. Neo-operations strategy. linking capabilitiesbased competition to technology. In: Gainor, G.H. (Ed.), Handbook of Technology Management. McGraw-Hill, New York, pp. 38.1-38.44.

Roth, A.V., Miller, J.G., 1992. Success Factors in Manufacturing, Business Horizons 35 (4), 73-81.

Ruiz-Maya, L., 1995. Análisis Estadístico de Encuestas: Datos Cualitativos, Editorial AC.

Santos Cumplido, F.J., 2001. La Calidad del Empresario Sevillano, Sevilla Siglo XXI. Diputación Provincial de Sevilla, Sevilla.

Saraph J.V. Sebastian, R.J., 1992. Human Resource Strategies for Effective Introduction of Advanced Manufacturing Technologies (AMT). Production and Inventory Management Journal, 1st quarter, 64-70.

Schroder, R., Sohal, A.S., 1999. Organizational characteristics associated with AMT adoption. Towards a contingency framework. International Journal of Operations and Production Management 19 (12), 1270-1291.

Schroeder, D.M., Congden, S.W., Gopinath, C., 1995. Linking competitive strategy and manufacturing process technology. Journal of Management Studies 32 (2), 163-189.

Shepherd, D.A., McDermott, C., Stock, G.N., 2000. Advanced manufacturing technology: does more radicalness mean more perceived benefits The Journal of High Technology Management Research 11 (1), 19-33.

Small, M.H., Chen, I.J., 1995. Investment justificatio of advanced manufacturing technology: an empirical analysis. Journal of Engineering and Technology Management 12 (1-2), 2755.

Small, M.H., Yasin, M.M., 1997. Advanced manufacturing technology: implementation policy and performance. Journal of Operations Management 15 (4), 349-370.

Sohal, A.S., 1997. A longitudinal study of planning and implementation of advanced manufacturing technologies. International Journal of Computer Integrated Manufacturing 10 (1-4), 281295.

Starr, M.K., 1989. Managing Production and Operations. Prentice-Hall, Englewood Cliffs, NJ.

Stobaugh, R., Telesio, P., 1983. Match manufacturing policies and product strategy. Harvard Business Review 61, 113-120.

Sun, H., Hjulstad, R., Frick, J., 1997. Implementations of advanced manufacturing technologies: an empirical study in Norway. In: Proceedings of the Fourth International Conference of the European Operations Management Association, Barcelona, pp. 555-560.

Swamidass, P.M., Kotha, S., 1998. Explaining manufacturing technology use, fir size and performance using a multidimensional view of technology. Journal of Operations Management 17 (1), 23-37.

Twigg, D., Voss, C.A., Winch, G.M., 1992. Implementing integrating technologies: developing managerial integration for CAD/CAM. International Journal of Operations and Production Management 12 (7-8), 76-91.

Vanderspek, P.G., 1993. Planning for Factory Automation: A Management Guide to World-Class Manufacturing. McGrawHill, New York.

Van de Ven, A.H., Ferry, D.I., 1980. Measuring and Assessing Organizations. Wiley, New York.

Ward, P.T., Duray, R., 2000. Manufacturing strategy in context: environment, competitive strategy and manufacturing strategy. Journal of Operations Management 18 (2), 123-138.

Wheelwright, S.C., Hayes, R., 1985. Competing through manufacturing. Harvard Business Review 65 (1), 213-223.

Woodward, J., 1965. Industrial Organization: Theory and Practice. Oxford University Press, Oxford. 